\title{
Labelled Loans and Human Capital Investments
}

\author{
Britta Augsburg, Bet Caeyers, Sara Giunti, Bansi Malde, Susanna Smets*
}

October 2019

\begin{abstract}
Liquidity constraints are known to significantly impede human capital investment decisions in developing countries. However, it is not obvious whether, and the extent to which, labelled microcredit - linked with the investment by name only - will boost human capital investments, particularly since money is fungible and a label is not a strong commitment. Drawing on a cluster randomised controlled trial of a sanitation microloan intervention in rural India, we show that labelled microcredit is effective in increasing sanitation investments. However, not all loans are used for sanitation investments. Testing predictions from a theoretical model that integrates loan labels provides novel evidence that loan labels influence household borrowing and investment decisions. Labelling of loans - which to date has not received much attention in the literature - is a viable strategy to improve uptake of lumpy preventive health investments.
\end{abstract}

JEL codes: O16, D14, G41, I12

*Affiliations: Augsburg - Institute for Fiscal Studies (IFS), UK (britta_a@ifs.org.uk); Caeyers - IFS, UK and FAIR, NHH (bet_c@ifs.org.uk); Giunti - University of Milano-Bicocca, Italy (sara.giunti@unimib.it); Malde - University of Kent and IFS (b.k.malde@kent.ac.uk); Smets - World Bank (ssmets@worldbank.org). Funding from the World Bank Strategic Impact Evaluation Fund and the ESRC Centre for the Microeconomic Analysis of Public Policy at the Institute for Fiscal Studies is gratefully acknowledged. Ethics approval was received from the University College London Research Ethics Committee, Project ID: 2168/008; and from the IRB of The Institute of Sustainable Development, Chennai, India. The evaluation is registered in the AEA Trial Registry, AEARCTR-0001955. We thank Orazio Attanasio, Sonia Bhalotra, Maitreesh Ghatak, Niels Hermes, Friederike Lenel, Florent Bedecarrats and participants at the EDePo seminar, Kent, UNU-WIDER conference, Oslo Microfinance Workshop, ISI Delhi Conference, CERMi, CSAE Conference, RES Conference, EDePo-STICERD workshop, Bristol EPIB workshop, LACEA-BRAIN workshop, and the CSAE Seminar series for useful discussions and suggestions. Felipe Brugues and Borja Perez-Viana provided excellent research assistance. We thank the implementing agency for their cooperation and endless patience through the project. All errors are our own. 


\section{Introduction}

Improving human capital is acknowledged to play a key role in fostering inclusive growth. However, there is widespread underinvestment in preventive health, an important human capital investment, in low-income settings (Dupas, 2011). Providing households with the option of paying for specific health products through microfinance ('bundled microfinance') has been shown to be effective in increasing take-up of malaria nets (Tarozzi et al., 2014), water connections and filters (Devoto et al., 2012; Guiteras et al., 2016) and safe toilets (BenYishay et al., 2017). However, such approaches are not only costly and challenging to scale-up - requiring either multiple skills and capital within one organisation, or effective coordination across multiple organisations - but they also restrict consumers' choice sets, potentially lowering their welfare. Labelled credit - associated with the investment through its name only - offers an alternative, relaxing liquidity constraints without tying consumers to a specific product. However, little is known about its effectiveness in boosting preventive health investments. Though they could encourage the intended investments if households are mental accounters, or believe that the lender will enforce loan use, the label is not a strong commitment mechanism. Loans could be diverted to other purposes, especially if they are characterised by other attractive attributes.

In this paper, we draw on a cluster randomised controlled trial (RCT) in rural Maharashtra, India, to study whether labelled credit is effective in increasing the adoption of an important lumpy preventive health investment - a safe toilet. Clients of a leading microfinance institution (MFI hereon) in randomly selected Gram Panchayats (clusters) were offered a new sanitation loan product, which was linked with sanitation through the loan label only. We study the impacts of the intervention on loan uptake, and sanitation investments and usage. Further, we specify a simple theoretical model of household borrowing and investment choices that integrates loan labels, which yields predictions allowing us to test whether loan labels influence household choices. Taking the predictions to the data yields support for this hypothesis.

Though considered to be an indispensible element of disease prevention and primary healthcare (e.g. the Declaration of Alma-Ata, 1978), the adoption of safe sanitation facilities remains low. This is a particularly salient issue in the context of India, where at the outset of our study in 2015 , over $60 \%$ of the close to 1 billion people defecating in the open globally resided (WHO/UNICEF, 2014). High rates of open defecation have been linked to poor health (Augsburg and Rodriguez-Lesmes, 2018; Spears, 2012; Kumar and Vollmer, 2013; Pickering et al., 2015 and Dickinson et al., 2015), and increased psychosocial stress, leading to worse human capital outcomes (Spears and Lamba, 2015), and constrained economic growth; making the scale of the problem urgent. The lack of access to safe sanitation is especially pronounced in our study areas - Latur and Nanded districts in Maharashtra: only 27 percent of households had a toilet in 2014, with a negligible minority using community or shared toilets.

The trial, conducted among clients of a leading MFI, made available microloans for sanitation in 40 randomly selected communities, 41 were allocated to control and received all other services as usual. The loans, offered at a lower interest rate relative to productive business investment loans, were to be used for the construction of a new toilet or the repair or upgrade of an existing one. Importantly, the loans were not bundled with a specific toilet or materials; households were left to their own devices to source 
materials and arrange construction. Moreover, though sanitation investments such as the construction of new toilets are easier to observe than many business investments, the implementing MFI did not otherwise incentivise or enforce intended use of this loan product. Thus, these loans can be considered to be purely labelled loans. The experiment is therefore in direct contrast with previously implemented RCTs around the use of microcredit for health investment, cited above, and in particular with respect to BenYishay et al. [2017] who show that demand for private toilets can be boosted significantly when offering microcredit for toilets bundled with the delivery of toilet construction materials to the doorstep of the borrower household.

Empirically, we find that households in our experiment demand the newly available product: 2.5 years after intervention roll-out, just over 18 percent of baseline clients took the sanitation loan. Loan take-up in our study context is in itself not surprising given the lower interest rate and no enforcement of loan use from the MFI. Turning to sanitation investments, we find, however, that the intervention resulted in a statistically significant increase in toilet uptake: 2.5 years after making the sanitation loan available, 9 percent of client households owned a toilet they would not have invested into without the new loan product. This is an economically significant effect in our context, accounting for around $38 \%$ of the increase in toilet uptake in treated communities over the course of the experiment. ${ }^{1}$ The estimated impact is within the range of other sanitation interventions in different contexts. Studies looking at impacts, as we do, on improved or hygienic toilets find effects ranging from no impact from a latrine promotion program in Bangladesh studied by Guiteras et al. [2015] to a 19 percentage point increase from a combination of awareness creation activities and subsidy provision in Madhya Pradesh, India studied by Patil et al. [2014]

These findings indicate that around $50 \%$ of sanitation loans did not trigger new sanitation investments. However, in addition to the construction of toilets, sanitation loans could be used for other sanitation investments, such as for rehabilitation, repair or upgrade of existing toilets. We find little evidence that this happened. Importantly for policy, we also find that the newly constructed toilets are mostly used, yielding a decrease of open defecation of around $10 \mathrm{pps}$, in line with the increased toilet uptake.

We then consider the role of the loan label in explaining the intervention impacts. To do so, we develop a simple model of household borrowing and investment which integrates household sensitivity to loan labels. A key insight that emerges from the model is that when client households are sensitive to labels, the label will induce them to make the investment associated with the new loan, and more so than when the loan is not labelled. Importantly, the model predicts that the increased sanitation investments should be accompanied by increased overall borrowing, except when households are sufficiently sensitive to loan labels and its liquidity constraints are not fully relaxed. In this case, households will instead substitute away from other (labelled) loans and investments. This is one of two predictions the model allows us to test empirically to establish that loan labels have a role to play in explaining the intervention impacts.

The second prediction is that the label will discourage households from taking the lower interest sanitation loan if they do not intend to make a sanitation investment. In line with these predictions, we

\footnotetext{
${ }^{1}$ Toilet uptake increased by close to 18 percentage points among the study sample in control communities from a base of $23.8 \%$ to $41.3 \%$ over the course of the intervention.
} 
find that over $70 \%$ of clients in the treated communities that borrowed from the MFI took a more expensive business loan even when they were eligible to take the sanitation loan. This is despite the fact that the weekly loan repayment installment, which clients are well aware of (potentially more so than the interest rate) made the difference in cost for these loans salient. Second, we find no evidence of increased overall borrowing. Instead, there is suggestive (though not statistically significant) evidence of substitution away from a similarly priced education loan. This would be consistent with an influence of loan labels if the sanitation loan did not fully relax liquidity constraints, which we show to be the case in this context.

In sum, our evidence allows us to establish that loan labels influence household borrowing and investment choices. At the same time, the fact that not all loans were used for new sanitation investment suggests that either some households are insensitive to the loan label or there are other constraints that prevent them from making the sanitation investments.

Having established the role of the label, our final contribution is to assess the channel through which the loan label affects households' borrowing and investment decisions. We argue that mental accounting is a key factor and that, indeed, microcredit is generally built on labelling loans for productive investment purposes, with the idea of simultaneously helping households make investments that increase their income, but also ensure repayment of their debt. Academic literature supports this notion that agents mentally categorize their financial outlays, showing that labelling is highly effective at protecting funds from being siphoned for other purposes (Bauchet et al., 2011) and helping households and individuals maintaining financial discipline (Shefrin and Thaler, 1988). We use novel data to rule out other potential channels through which the label might act, namely that of information and salience, as well as perceived enforcement of loan use and reputation building.

These findings contribute to a growing literature studying the role of labelling (sometimes also thought of as 'nudges' Thaler and Sunstein, 2008), and of the fungibility of money. There is by now vast evidence that how funds are grouped and labelled influences financial decisions and preferences of individuals, thereby violating the economic principle of fungibility ([Shefrin and Thaler, 1988, Thaler, 1990, 1999, Abeler and Marklein, 2017]). ${ }^{2}$ Labelling has further been considered highly effective at protecting funds from being siphoned for other purposes (Bauchet et al., 2011), helping households and individuals maintaining financial discipline (Shefrin and Thaler, 1988). Little is, however, known in how far labelling matters for borrowing and investment decisions, in particular in low income settings and with respect to (preventive) health investments. A notable exception is a study by Dupas and Robinson [2013], which shows in the context of Kenya that simply providing a labelled safe space to keep money for health expenditures significantly increases savings for this purpose. This finding is in line with evidence on educational investments: De Arcangelis et al. [2015] and Benhassine et al. [2015] demonstrate that adding education labels to remittances and cash transfers result in large gains to households' educational investments in the Philippines and Morocco respectively. ${ }^{3}$ However, labelling

\footnotetext{
${ }^{2} \mathrm{~A}$ large literature in public finance also finds evidence of non-fungibility,referred to as the 'flypaper effect'. For example, Hines and Thaler [1995] discuss how, contrary to what economic theory would predict, local governments that receive earmarked payments for particular kinds of expenditure (e.g. schools) increase spending on that activity by the full amount of the grant.

${ }^{3}$ Interestingly, Karlan and Linden [2018] demonstrate that stricter commitments can deter participation in a school-
} 
of savings is not always effective in increasing human capital investments. Lipscomb and Schechter [2018] find that earmarked savings accounts and deposit requirements, both inspired by mental accounting models, do not increase demand for a more expensive sanitation service, while high subsidies do so.

Our findings also contribute to a growing literature on the adoption of lumpy human capital investments, specifically private household toilets. A small but growing number of studies rigorously demonstrate that liquidity constraints limit adoption: Guiteras et al. [2015] show that the provision of subsidies increases toilet take-up in rural Bangladesh; while an awareness creation campaign yields close to no impact and Peletz et al. [2017] and Peletz et al. [2019] show that households' willingness to pay for latrines is below market prices in Tanzania and Kenya respectively, with a lack of cash cited as the key underlying reason. However, as shown by BenYishay et al. [2017], providing microcredit increases willingness-to-pay and actual investments when bundled with the toilet. We contribute to this literature by showing that labelled loans can be effective in encouraging adoption and use of private household toilets even when the toilet is not bundled with the loan.

The rest of the paper is structured as follows. The next section describes the context of the study and the sanitation loan product. Section 3 discusses the experimental design and data. Thereafter, Section 4 outlines our empirical strategy, and is followed by a presentation of our main empirical findings in Section 5. Section 6 studies the role of the loan label in explaining the intervention impacts. Section 7 concludes.

\section{Context and intervention}

\subsection{Context}

Our study concentrates on a number of communities in 5 blocks of Latur and Nanded district in the South-Eastern part of Maharashtra, India. Maharashtra, with its capital Mumbai, is one of the largest Indian states, counting approximately 100 million people (GoI, 2011a). It is also the second richest state in the country in terms of per capita income, though incidence of poverty remains close to the national average, implying severe inequalities within the state (GoM, 2012). The study districts, Latur and Nanded, are among the lagging districts of Maharashtra along a number of different dimensions. The 2011 Human Development Index values for Latur and Nanded rank them close to the bottom for the state (GoM, 2018). Further, the literacy rates for Latur and Nanded stood at 79 percent and 76.9 percent respectively in 2011, below the state-level rate of 82.9 percent. Agriculture is the main economic activity in these districts with over 70 percent of the population engaged in it (GoI, 2011c; GoI, 2011b). Toilet ownership rates in Latur and Nanded districts lag behind those in rural Maharashtra and rural India. Data from the 2012-13 District Level Health Survey (DLHS-4) shows that around 23.7 percent of rural households in Latur and Nanded had a toilet, compared with rural Maharashtra (38 percent) and rural India (55.8 percent).

based commitment savings program for educational expenses in Uganda. Similarly, Afzal et al. [2018] analyse demand for commitment in microfinance contracts and find that, while they may induce financial discipline, many used in practice may be seen as overly restrictive ex ante, even for a population with a demonstrated demand for commitment products. 
Financing was reported as the major constraint for not having a toilet, with 83 percent of households in our study reporting affordability or price as the key reason for not having a toilet. This is not very surprising since the typical cost of a toilet recommended by the Government of India's flagship sanitation program, the Swachh Bharat Mission (SBM) - Gramin amounts to around 20 percent of annual income for the average household in our study (Ministry of Drinking Water and Sanitation, 2014). Prior to the roll-out of the intervention we study, sanitation investments were predominantly financed through a combination of savings (87 percent), government subsidies (12 percent) and transfers and informal loans (7\%). Setting aside such a significant sum would be challenging for poor rural households, particularly given other more pressing demands on household budgets. Formal financial services are generally available in the study areas, with a number of microfinance institutions providing credit to poor households. However, over the period of the experiment, few institutions provided credit for non-income generating purposes such as human capital investments; and none provided credit for sanitation.

Government efforts to improve sanitation coverage in rural India, implemented through the SBM scheme, comprise of two core components: (i) encouraging household demand for toilets through a one-off behavioural change campaign, modelled roughly on the widely used Community Led Total Sanitation approach, and (ii) alleviation of financial constraints for specific households through the provision of subsidies worth about INR 12,000 (USD 180) in the study area. ${ }^{4}$ This amount is insufficient to cover the cost of toilets typically constructed by households in these communities: for example, control households in our study report spending on average INR 25,000 (USD 375) in toilet construction costs. Moreover, given concerns that households could take the subsidy but spend it on non-sanitation purposes, the subsidy is structured so that households can avail a part of it once construction preparation has started, with the rest available once construction is completed. These features suggest that the microcredit program studied could complement the SBM subsidy. This is studied in detail in a companion paper, Augsburg et al. [2019].

\subsection{Intervention}

It is in this context that our implementing partner, a large MFI active in five states in India, referred to as the MFI hereon, introduced a sanitation loan product for their existing clients. The MFI provides financial - primarily microcredit and microinsurance - and non-financial services to groups of women from low-income households in rural and semi-urban areas. It offers a wide range of loans including income generating, emergency, festival, and education loans. The MFI started providing sanitation loans in 2009, introducing these in our study area from 2014 onwards. At the time of the intervention roll-out, the partner MFI was the only provider of sanitation loans in the study area.

The sanitation loan offered by the MFI covers a maximum amount of INR 15,000 (USD 225), incurring an interest rate of initially 22 percent per annum (later reduced to 20 percent and then 18 percent) at a declining balance over a 2-year repayment period. The interest rate reductions were part of a general policy change across all loans offered by the MFI in response to a reduction in its cost of capital. The

\footnotetext{
${ }^{4}$ We use the USD to INR exchange rate from the XE currency converter on 19 June 2018: 1 INR $=0.015$ USD.
} 
loan amount is sufficient to cover the costs of the type of safe toilet recommended by SBM. However, it is lower than the INR 25,000 (USD 375) cost reported by the average control group household. In addition to the interest, loan costs include a processing fee of 1.1 percent of the total amount and a INR 306 life insurance premium. Clients could repay the loans through regular weekly or bi-weekly payments. However, in practice, all chose to make weekly repayments.

The loan amount is higher than that for other non-productive loans offered by the MFI, and carries a similar or lower interest rate and a longer repayment period. ${ }^{5}$ Business loan products are of a similar or larger size, but have a higher interest rate. There is no collateral requirement but loans are provided through joint-liability lending groups of 5 - 10 members. Only women that have been clients of the MFI for at least one year are eligible to take a sanitation loan. Each client can take one sanitation loan only and this loan can be taken in parallel to other loans. The MFI requires clients interested in applying for a sanitation loan to obtain agreement from their spouses before the application is processed. A credit bureau check is conducted for all loan applications, and applications are rejected if the client does not satisfy the criteria set out by the Reserve Bank of India (RBI). ${ }^{6}$ Table 1 summarises the sanitation loan characteristics.

Table 1: Sanitation loan characteristics

\begin{tabular}{ll}
\hline \hline Amount: & Up to INR 15,000 \\
Interest rate: & $22 \%$ (later 18\%) per annum on a declining balance \\
Loan maturity: & 2 years \\
Payment Frequency: & Weekly/Bi-weekly basis \\
Collateral: & None, but joint-liability \\
Cost of the loan: & $19.9 \%-24.1 \%$ of the amount disbursed depending on interest rate \\
Other costs: & Processing fee of $1.1 \%$ of principal and Rs 306 for life insurance premium \\
\hline \hline
\end{tabular}

\subsection{Sanitation loan is a labelled loan}

This sanitation loan, as with other loan products provided by the MFI, can be classified as a 'labelled' loan for several reasons: First, while the MFI provides loans for many different purposes - income generation, education, festival, etc. - none is bundled with the specific investment and all funds are disbursed directly to the client. This is also the case for the sanitation loan: loans were not bundled with any specific toilet model or construction material, and the MFI did not provide any advice or guidance on the construction of a toilet, available masons, types of toilet, etc. Clients were free to install a toilet of their own choice, which is in contrast to other studies of microcredit loans for health

\footnotetext{
${ }^{5}$ Details on the core loan products offered by the MFI are provided in Table A.1 in Appendix A.

${ }^{6}$ The Reserve Bank of India imposes the following requirements on rural microfinance customers from October 2015 (pre-October 2015): (1) Annual household income of at most INR 100,000 (INR 60,000); (2) Total indebtedness of at most INR 100,000 (INR 50,000) excluding education and medical expenses; (3) Overall loan amount of at most INR 60,000 (INR 35,000) in the first cycle and INR 100,000 (INR 50,000) in subsequent cycles; (4) Loan tenure should not be less than 24 months for any loan amount in excess of INR 30,000 (INR 15,000). In addition, at least 50\% (75\%) of the MFI's portfolio should be comprised of income generation loans.
} 
investments where loans were bundled with specific products (e.g. BenYishay et al., 2017, Tarozzi et al., 2014 and Guiteras et al., 2016).

Second, actual loan use is not consistently monitored or enforced by the MFI. When monitoring is conducted, it relies primarily on reporting by the client or her group members. Among our sample, 15 percent of clients that took a sanitation loan report that no monitoring check whatsoever was done; 53 percent report that monitoring was done through a loan official asking herself or a group member about how the loan was used; while only 30 percent of clients report that, consistent with the MFI's procedures, loan officers visited their home to check whether they owned a toilet when applying or to check its use. Moreover, loan officer checks are not monitored or incentivised by the MFI. To give some supportive statistics from our context: 26 percent of clients that took a sanitation loan reported using it for the construction of a new toilet, despite already owning one (that was verified by survey interviewers) before the intervention began.

Third, the MFI does not enforce or incentivise loan use in any specific manner, such as through larger loan sizes or lower interest rates for clients; or through incentives and/or sanctions for loan officers. As with many other MFIs, senior management's core focus is on minimising default and late repayment. Conversations with the top management of the MFI, and staff involved in loan approval - which occurs in the head office - indicate that past loan use is not taken into consideration when approving a loan application. By contrast, new loans are not approved if a client is late in repaying an existing loan orhas defaulted on a past loan. In line with this, we find that 34 percent of clients who took a sanitation loan and did not have a toilet either at the roll-out of the intervention or at the time of our endline survey took a subsequent loan over the course of our experiment. Further, 89 percent of clients who took a sanitation loan and had a toilet before intervention implementation also obtained a subsequent loan from the MFI. ${ }^{7}$

\section{The Experiment}

\subsection{Experimental Design}

Our study covers 81 Gram Panchayats (GPs) within Latur and Nanded districts. A GP is the smallest administrative unit in India, and is charged with the delivery of a number of programs, including the Government's flagshipSBM policy. The study GPs were selected based on two criteria: (i) the MFI had existing operations and (ii) no sanitation activities had been undertaken by the MFI in the GP. A total of 133 GPs satisfied this criterion, of which 120 were randomly selected to be part of the study. Stratified randomisation was used in order to boost statistical power. Strata were defined based on the branch of the MFI and size of the GP, where GPs with fewer than 480 households were classified as 'small', while the rest were classified as 'large'. Of the 120 study GPs, 40 were randomly (within strata) selected to receive the sanitation credit program and 41 selected (within strata) to be control

\footnotetext{
${ }^{7}$ Though these clients could have used the sanitation loans to repair or upgrade their toilets, as we show in Section 5.2 , very few clients chose to do this.
} 
GPs. ${ }^{8}$ All study GPs, including control GPs, continued to receive all other activities from the MFI. Sanitation loans were disbursed from February $2015 .^{9}$

\subsection{Data}

Our analysis draws on three sources of data: (i) an extensive household survey collected by the authors (primary survey data); which is linked with (ii)administrative loan data from the MFI partner; and (iii) credit bureau reports of loans taken by sampled clients from all microfinance providers in the study area. We discuss each of these in turn.

\subsubsection{Primary Survey Data}

A survey on a sample of clients active in November 2014 (prior to intervention rollout - referred to as baseline from hereon), and their households, was conducted in August and September 2017, about 2.5 years after sanitation loans were first made available. 2,841 clients (on average 24 per GP) - 1,253 in treated GPs and 1,588 in control GPs - were interviewed by an independent survey company (with interviewers blind to treatment status). ${ }^{10,11}$ Overall, we sampled around 75 percent of all clients active at baseline. Our sampling strategy - detailed in Appendix B - focused on including clients from the same lending centre (kendra), so as to collect information on joint liability groups. Though it is not a random sample of clients, our high sampling rate ensures that the obtained sample is mostly representative of clients active at baseline. ${ }^{12}$ Nonetheless, the analysis will include controls for any potential distortions introduced by the sampling strategy.

The household survey, administered to the household head, collected detailed information on household demographics, labour supply, and borrowing from formal and informal sources. A separate client survey elicited information on a number of different dimensions of the client's joint-liability group, and interactions with the microfinance provider. Detailed information on sanitation investment was also collected, including type of toilet owned, construction date and costs, and defecation behaviour of all

\footnotetext{
${ }^{8} \mathrm{~A}$ further 39 GPs were randomly selected (within strata) to receive another program, whose impacts are considered elsewhere.

${ }^{9}$ Care was taken throughout the study period to ensure that the integrity of the research design was preserved. Authors conducted briefing sessions with the branch staff of the MFI before the start of the intervention, provided a pictorial reminder of the GPs where sanitation credit could not be offered, and monitored the disbursement of sanitation credit to control GPs using the MFI's administrative monitoring system. As a result, contamination of the control group was minimal: a small number of loans (27) were disbursed in the control group a few months after intervention roll-out, but this was swiftly stopped once noticed by the research team.

${ }^{10}$ For a sub-sample of these households, we have baseline data collected before the intervention began. Attanasio et al. [2015a] use these data to show that the samples are balanced at baseline.

${ }^{11}$ Around 7 percent of sampled households, balanced across treatment and control GPs, could not be interviewed because of refusals or lack of availability, and were replaced with back-up respondents. The non-availability/refusal rate is similar for households surveyed at baseline, and those included only in the endline sample.

${ }^{12}$ T-tests comparing the characteristics of the obtained sample with the population of active clients reveal that the samples are similar on most observed characteristics other than small differences in the proportion of clients from backward castes, and client age. In particular, the sample includes fewer clients from backward castes and younger clients than the population of active clients.
} 
household members. The information on the construction date allows us to obtain a retrospective measure of toilet ownership at baseline. ${ }^{13}$ For households who reported having a toilet, survey enumerators verified it directly and made observations on its appearance, the quality of the overground structure, and cleanliness. We use the enumerator verified observation of the toilet as the measure for toilet ownership. ${ }^{14}$

Sanitation interventions are ultimately interested in encouraging the take-up and use of safe sanitation facilities - which separates excreta from human contact effectively. Applying guidelines from the World Health Organisation and UNICEF (WHO/UNICEF, 2017), we compute an indicator for safe toilet ownership. ${ }^{15}$ Almost all (99.6 percent) of toilets in our data are classified as safe toilets, implying that toilet ownership captures safe toilet ownership in this context.

\subsubsection{Administrative Data}

Our analysis will also draw on detailed adminstrative data from the MFI for the surveyed clients. This contains information on all loans taken from the MFI during the study period, including amount borrowed (per loan), repayment amount, the date of disbursement, tenure, purpose of the loan and default. This provides us with reliable information on the disbursement of all loans, allowing us to track trends in loan uptake over time. ${ }^{16}$

\subsection{Sample Descriptives and Sample Balance}

Table 2 presents descriptive statistics for our sample of clients and their households using endline survey data. We thus present variables that are unlikely to have been affected by the intervention itself. Column (2) of Table 2 displays the variable mean for the control group, while Columns (3) and (4) present the difference in means between the control and treatment group, and the $p$-value for a $t$-test of equality of these means respectively.

\footnotetext{
${ }^{13}$ This retrospective measure of toilet ownership matches well with baseline data available for a sub-sample of households. The two measures are identical in $78 \%$ of cases, with the remaining differences likely a result of misreporting or recall errors in the construction date reported at endline. Importantly, this is balanced across treatment groups; which should thus not lead to bias in the impact estimates. Indeed, when we estimate difference-in-difference models using the sample for whom baseline and endline data was collected (and so actual baseline toilet ownership is known), we obtain very similar impacts as those reported in Section 5.

${ }^{14} \mathrm{~A}$ comparison of household reports with interviewer observations indicates that toilet ownership was mostly accurately reported. Only in $4.53 \%$ of households did the interviewer observation deviate from that of the household's own report. In $2.34 \%$ of cases, the household not allow the interviewer to check the toilet. Some of these deviations could be a result of households having started the toilet construction process, for example, by hiring a contractor and/or purchasing the construction materials, but without actual construction having commenced.

${ }^{15}$ Safe toilets include flush/pour flush to piped sewer system, septic tanks, pit latrines, VIP, pit latrines with slab, composting toilets, biogas systems and urine diversion dehydration toilets.

${ }^{16} \mathrm{We}$ also assess the robustness of estimated impacts on microfinance borrowing to recall and reporting errors using credit bureau data. Following regulations introduced by the Reserve Bank of India in 2011, all microfinance institutions are required to report on all loans outstanding for each client on a monthly basis. We obtained this information, with consent, for around 88 percent of clients in our sample. For the remaining 12 percent, the partner MFI did not have all the information required by the credit bureau in order to avail of these records at the time when they were requested (December 2017). Relative to the full sample of clients, clients for whom we obtained credit bureau data are more likely to be married, and less likely to live in female-headed households. Household heads also tend to have more years of education. This is shown in Table OA-B.1 in the Online Appendix.
} 
Table 2: Sample descriptives and sample balance

\begin{tabular}{|c|c|c|c|c|}
\hline$(1)$ & $\begin{array}{c}(2) \\
\text { Control }\end{array}$ & $\begin{array}{c}(3) \\
\text { SL - Control }\end{array}$ & $\begin{array}{c}(4) \\
\text { P-value }\end{array}$ & $\begin{array}{l}(5) \\
\mathrm{N}\end{array}$ \\
\hline HH head religion: Hinduism (\%) & $\begin{array}{c}67.8 \\
(3.57)\end{array}$ & $\begin{array}{l}-2.47 \\
(5.28)\end{array}$ & 0.642 & 2821 \\
\hline HH head religion: Islam (\%) & $\begin{array}{c}18.6 \\
(3.90)\end{array}$ & $\begin{array}{c}3.74 \\
(5.61)\end{array}$ & 0.507 & 2821 \\
\hline $\mathrm{HH}$ head religion: Buddism (\%) & $\begin{array}{l}12.8 \\
(2.35)\end{array}$ & $\begin{array}{l}-0.95 \\
(3.28)\end{array}$ & 0.774 & 2821 \\
\hline $\mathrm{Nr}$ of $\mathrm{HH}$ members & $\begin{array}{c}5.01 \\
(0.084)\end{array}$ & $\begin{array}{l}0.030 \\
(0.11)\end{array}$ & 0.792 & 2821 \\
\hline HH head caste: Backward (\%) & $\begin{array}{c}34.2 \\
(4.08)\end{array}$ & $\begin{array}{l}-2.55 \\
(5.38)\end{array}$ & 0.636 & 2821 \\
\hline HH head caste: Scheduled (\%) & $\begin{array}{c}41.3 \\
(4.11)\end{array}$ & $\begin{array}{l}-1.23 \\
(6.04)\end{array}$ & 0.840 & 2821 \\
\hline HH head caste: General (\%) & $\begin{array}{c}24.0 \\
(4.04)\end{array}$ & $\begin{array}{c}3.34 \\
(5.86)\end{array}$ & 0.570 & 2821 \\
\hline Gender of the HH head - male (\%) & $\begin{array}{c}89.8 \\
(1.02)\end{array}$ & $\begin{array}{c}1.54 \\
(1.38)\end{array}$ & 0.269 & 2821 \\
\hline Age of the $\mathrm{HH}$ head in years & $\begin{array}{c}45.3 \\
(0.48)\end{array}$ & $\begin{array}{c}0.17 \\
(0.60)\end{array}$ & 0.777 & 2821 \\
\hline Years of education $\mathrm{HH}$ head & $\begin{array}{l}5.86 \\
(0.20)\end{array}$ & $\begin{array}{c}0.14 \\
(0.28)\end{array}$ & 0.627 & 2821 \\
\hline $\mathrm{HH}$ head is married (\%) & $\begin{array}{c}91.4 \\
(0.93)\end{array}$ & $\begin{array}{c}1.02 \\
(1.22)\end{array}$ & 0.408 & 2821 \\
\hline Dwelling owned by HH members (\%) & $\begin{array}{c}96.1 \\
(1.03)\end{array}$ & $\begin{array}{c}0.64 \\
(1.28)\end{array}$ & 0.619 & 2821 \\
\hline Dwelling structure: Pucca House & $\begin{array}{l}17.7 \\
(2.41)\end{array}$ & $\begin{array}{c}2.54 \\
(3.15)\end{array}$ & 0.423 & 2821 \\
\hline Dwelling structure: Semi-pucca house & $\begin{array}{c}65.6 \\
(3.09)\end{array}$ & $\begin{array}{l}-0.71 \\
(4.09)\end{array}$ & 0.863 & 2821 \\
\hline HH owns a BPL card (\%) & $\begin{array}{c}59.1 \\
(2.06)\end{array}$ & $\begin{array}{l}-1.15 \\
(3.32)\end{array}$ & 0.731 & 2821 \\
\hline HH owns an APL card (\%) & $\begin{array}{c}27.8 \\
(1.88)\end{array}$ & $\begin{array}{l}-1.29 \\
(3.04)\end{array}$ & 0.674 & 2821 \\
\hline Primary activity HH: Agriculture (\%) & $\begin{array}{c}50.6 \\
(3.89)\end{array}$ & $\begin{array}{c}2.89 \\
(5.05)\end{array}$ & 0.569 & 2915 \\
\hline Primary activity HH: Waged employment (\%) & $\begin{array}{c}27.5 \\
(2.34)\end{array}$ & $\begin{array}{l}-2.00 \\
(3.34)\end{array}$ & 0.552 & 2821 \\
\hline $\mathrm{HH}$ owned a toilet at baseline (reconstructed) (\%) & $\begin{array}{c}23.8 \\
(2.06)\end{array}$ & $\begin{array}{c}2.95 \\
(2.94)\end{array}$ & 0.318 & 2821 \\
\hline
\end{tabular}

Notes: SL equals sanitation loan arm. Standard errors clustered at the village level are shown in parentheses. ${ }^{*},{ }^{* *},{ }^{* * *}$ indicate significance at the 10, 5 and 1 percent level. HH stands for household. Column 2 reports mean and standard deviation (in parenthesis) for each variable in the control group. Column 3 reports differences in means between SL and Control arms. Toilet ownership at baseline is reconstructed from toilet construction dates reported at endline. If a toilet was in the dwelling when household moved in we consider number of years HH head lived in the household as a proxy of construction date. 
Two thirds of the study households are Hindu, and have on average five members. Fewer than a quarter of households are from general castes (24 percent), with 41.3 (34.2) percent belonging to scheduled (backward) castes. Household heads are mostly male (90 percent), married (91 percent), aged 45 years on average, and have 6 years of education on average. The vast majority of households (96 percent) live in a dwelling they own, with 66 percent of dwellings being of moderate quality (semi-pucca) and 18 percent being high quality (pucca). Around 59 percent of the sample holds a BPL card, while 28 percent has an Above Poverty Line (APL) card. A majority of households - 52 percent - report receiving wages from agricultural labour and/or from cultivation or allied agricultural activities; while 28 percent receive wages from employment outside agriculture. The baseline (reconstructed) measure of toilet ownership indicates that only 25 percent of control group households owned a toilet at baseline. ${ }^{17}$

Table OA-A.1 in the online appendix compares the study sample with rural households in the study districts, in rural Maharashtra and in rural India. The study sample is comparable to these populations in terms of caste composition, religion (though with a slightly higher proportion of Muslims) and toilet ownership, but has a much higher concentration of households with BPL cards and landless households. Columns (3) and (4) indicate small, but statistically insignificant differences in the means of these variables between the treatment and control group. This confirms that the randomisation was successful in creating observationally equivalent groups. Importantly, we find no significant difference in one of our key outcomes of interest - toilet ownership - between the twogroups at baseline. ${ }^{18}$

\section{Empirical Model}

The randomisation provides a clean and credible source of identification to estimate impacts of the sanitation microloan intervention. To do so, we estimate specifications of the following form:

$$
Y_{i v}=\alpha_{0}+\alpha_{1} \text { Treatment }_{v}+\beta X_{i v}+\theta_{v}+\varepsilon_{i v}
$$

where $Y_{i v}$ is the outcome for household $i$ in GP $v$. Our key outcomes of interest are uptake of sanitation loans, sanitation investments and defecation behaviour; though we will later study impacts on borrowing behaviour when investigating mechanisms driving the impacts. Treatment $v_{v}=1$ if the sanitation loan was introduced in GP $v$ and 0 otherwise; $X_{i v}$ includes controls that help to increase power and precision, controls to account for potential distortions due to the sampling strategy, and interviewer fixed effects. The former were chosen to include those that most explain variation in toilet ownership among control households at endline. The key variable satisfying this criterion is toilet ownership at baseline, implying that we are in fact estimating an ANCOVA specification when estimating impacts on toilet ownership. ${ }^{19}$

\footnotetext{
${ }^{17}$ This matches closely with the 2012 baseline survey conducted by the Ministry of Drinking Water and Sanitation, which yields a toilet ownership rate of 27.4 percent for the study GPs (Ministry of Drinking Water and Sanitation, 2014)

${ }^{18}$ Reassuringly, we also find no systematic differences in observed characteristics between the two groups when we repeat the same exercise with baseline data collected prior to the intervention roll-out for a sub-sample of clients and their households (Attanasio et al., 2015a).

${ }^{19}$ An alternative would be to estimate a difference-in-difference specification. However, McKenzie [2012] shows that when analysing an RCT experiment with two survey rounds, ANCOVA provides greater improvements in power relative
} 
Controls for potential distortions due to the sampling strategy include an indicator for having a child aged less than 2 years at baseline, and the ratio of number of sampled clients to village size. Finally, we strata dummies, $\theta_{v}$.

The key parameter of interest is $\alpha_{1}$, which provides the intention-to-treat (ITT) estimate. This compares average outcomes for sampled clients active at baseline in the treatment group, regardless of whether they took a sanitation loan with those for similar (active) clients in the control group. This allows us to interpret the experimental intervention as a policy and thus learn about its impact on the population served by the MFI. The focus on clients active at baseline ensures that the estimates are not biased by households that are particularly motivated to invest in a toilet joining the MFI to obtain a sanitation loan. The experimental design also allows us to estimate intervention impacts over and above any other activities promoting sanitation across the study GPs over the course of the experiment. This is important in this context given the Government of India's SBM policy was rolled out, by chance, at almost the same time as the sanitation loan intervention. Augsburg et al. [2019] find that SBM was implemented in a majority of treatment and control GPs with, if anything, a slightly higher implementation rate in control GPs (80 percent vs. 72 percent of treatment GPs).

In terms of inference, we cluster standard errors at the GP level. However, we also check the robustness of our findings to multiple hypothesis testing using the step-down procedure proposed by Romano and Wolf [2005]. Each table reports p-values adjusted for hypotheses tested within the table, while Table C.1 in Appendix C reports the p-values adjusted for all hypotheses tested in the paper.

\section{Results}

We report intervention impacts on the key outcomes of interest: sanitation loan take-up, sanitation investments and sanitation behaviour.

\subsection{Sanitation loan uptake}

Figure 1 displays the evolution of sanitation loan take-up over the course of the study using the MFI administrative data. ${ }^{20}$ The Figure shows a steady increase in the cumulative number of sanitation loans per client (y-axis) since intervention roll-out in February 2015 (x-axis) so that by the time of the endline survey, around 20 percent of clients in treatment GPs had taken a sanitation loan. A small number of loans - 21 in total - were also provided in the control areas, mainly driven by clients asking for these loans; rather than loans being (mistakenly) offered to control clients.

to differences-in-differences, particularly when the autocorrelation in the dependent variable is low. In analysis available on request, we estimated the impacts on toilet ownership using a differences-in-differences specification for the sub-sample for whom baseline data is available and found very similar impacts as with the ANCOVA specification.

${ }^{20} \mathrm{We}$ also collected loan uptake information from the clients directly. We find minimal differences in the two data sources: $4 \%$ of clients report taking a sanitation loan that does not appear in the administrative data and, similarly, $4 \%$ of clients reported to have taken a sanitation loan in the administrative data did not report taking one in the survey data. The fact that the frequency of inclusion error is exactly the same as the frequency of exclusion error suggests that misreporting is likely to be random which gives us confidence in the reliability of both datasets. 
Figure 1: Sanitation loan uptake during the intervention

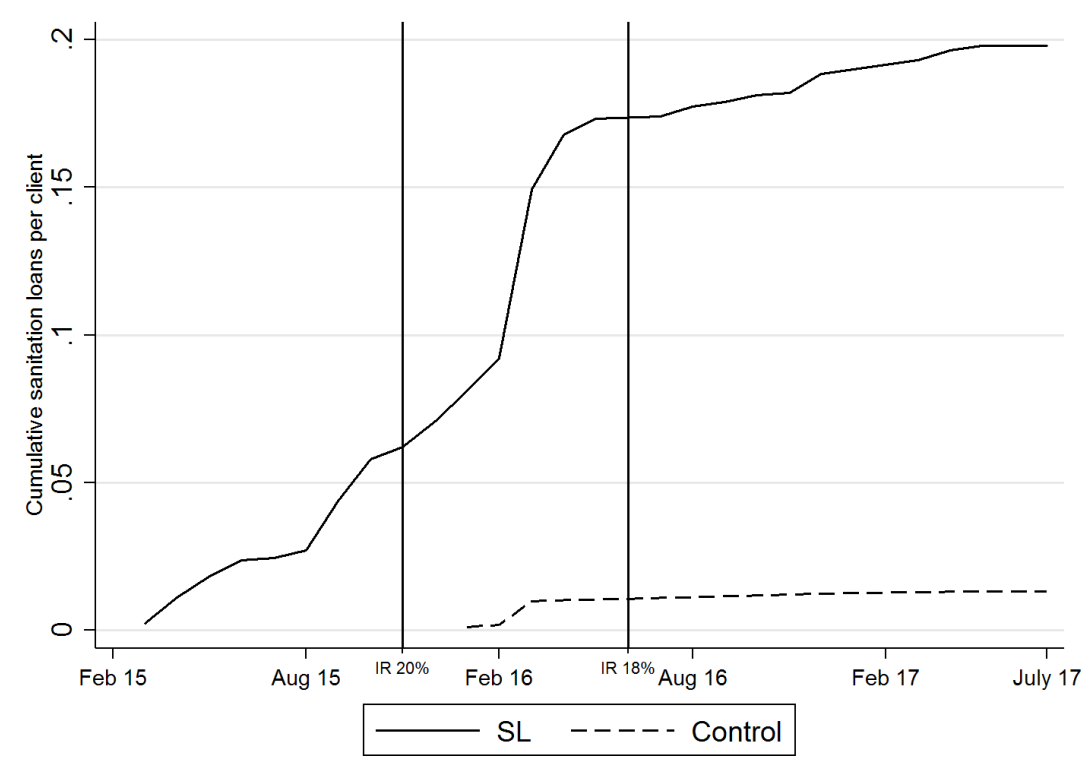

Notes: Source: Administrative data from MFI. The vertical lines mark reductions in interest rates, which occurred across all loan products in November 2015 (to $20 \%$ ) and June 2016 (to $18 \%$ ).

Table 3 displays the coefficient from estimating equation (1) with sanitation loan uptake as the dependent variable. The estimate indicates a statistically significant impact (at the 1 percent level) of 18 percentage points of the intervention on uptake of the sanitation loan.

Several factors could explain the magnitude of loan take-up. First, the loan was labelled for a human capital investment purpose, for which (monetary) returns might not be realised until after the loan repayment period has passed. Thus, households will take the loan for sanitation investments only if they can afford to make the loan repayments from other sources, which might rule out many households in our context. Second, the study area experienced two major macroeconomic shocks over the study area, which depressed demand for microfinance loans. Latur and Nanded saw a severe drought in 2016 , which was later followed by demonetisation - where the Indian Government withdrew all INR 500 and INR 1000 notes from circulation overnight - at the end of 2016. Both of these led to a reduction in loan disbursement by the MFI, which is apparent in a slowdown of loan take-up in 2016 and early 2017 on not only sanitation loans, but also on other loan products (not shown).

Third, households might perceive the benefits from safe sanitation to be too low to make it worthwhile to take the sanitation loan at the offered interest rate. More generally, we note that the sanitation loan take-up rate is comparable with those found by other randomised controlled trials on microfinance, which study income generating loans. Studies by Banerjee et al. [2015b], Tarozzi et al. [2015] and Angelucci et al. [2015], which sampled households most likely to be targeted by the relevant microfinance providers as potential clients, encountered loan take-up rates of 17-19 percent.

Take-up of the sanitation loan need not imply a similar increase in sanitation investments. The san- 
Table 3: Intervention impact on sanitation loan uptake

\begin{tabular}{|c|c|}
\hline & $\begin{array}{c}\text { Sanitation } \\
\text { Loan }\end{array}$ \\
\hline SL & $\begin{array}{l}0.182^{* * *} \\
(0.0358)\end{array}$ \\
\hline Cluster-robust p-value & {$[0.0000]$} \\
\hline Covariates & Yes \\
\hline $\begin{array}{l}\text { Control mean } \\
\mathrm{N}\end{array}$ & $\begin{array}{c}0.0133 \\
2821\end{array}$ \\
\hline \multicolumn{2}{|c|}{$\begin{array}{l}\text { Notes: SL equals sanitation loan arm. Stan- } \\
\text { dard errors clustered at the village level are } \\
\text { shown in parentheses. } *, * *, * * * \text { indicate } \\
\text { significance at the } 10,5 \text { and } 1 \text { percent level. } \\
\text { Romano-Wolf p-value corresponds to cluster } \\
\text { robust p-value. Covariates: Toilet ownership } \\
\text { at baseline, presence of a child aged } 0-2 \text { at } \\
\text { baseline, ratio of number of sampled clients to } \\
\text { village size, strata dummies and village fixed } \\
\text { effects. Data source: MFI administrative data } \\
\text { (dependent variable), household survey data } \\
\text { (covariates). }\end{array}$} \\
\hline
\end{tabular}

itation loan could simply displace financing sources for sanitation investments that households would have made even in the absence of the intervention. Similarly, the lower interest rate might also attract households seeking to borrow for non-sanitation purposes. Alternatively, households might face unexpected shocks, or additional constraints that prevent them from using the sanitation loan for sanitation investment. Thus, we next examine impacts on sanitation investments.

\subsection{Sanitation investments}

The sanitation loan could have been converted to sanitation investments in one of two ways: either by allowing the client to make an investment that would not be made in the absence of the intervention, which we will refer to as new investments; or by allowing her to use the credit instead of another funding source, such as savings, for investments she would have anyways made (which we will refer to as pre-planned investments). From a policy perspective, the key parameter of interest is the former, i.e. whether the provision of credit for sanitation induces new sanitation investments, which is the parameter the RCT design allows us to robustly identify. We will however also discuss the use of loans for sanitation investments instead of other funding.

We distinguish between two types of sanitation investments that could have been made with the loans: (i) construction of a new toilet, or (ii) upgrade or repair of an existing one. Clients' reports of what they used the sanitation loan for (Table 4) indicates that the vast majority (73 percent) used it for the construction of a new toilet, with only 5 percent reporting using it for toilet upgrade or repair. A small proportion of clients ( 7 percent) report using the loan for sanitation and other purposes; and 16 percent report using it for non-sanitation purposes. Thus, the primary reported reason for taking a sanitation loan was to construct a new toilet.

We measure impacts on the construction of new toilets more formally by estimating equation (1) with 
Table 4: Reported loan use

\begin{tabular}{lcc}
\hline \hline Investment & Nr. & $\%$ \\
\hline New toilet & 146 & $73 \%$ \\
Upgrade & 7 & $4 \%$ \\
Repair & 2 & $1 \%$ \\
Sanitation \& other & 14 & $7 \%$ \\
Other only & 31 & $16 \%$ \\
Total & 200 & $100 \%$ \\
\hline \hline Notes: Data source: Client survey and MFI adminis- \\
trative data. Sanitation loan usage was reported for \\
those clients who took a sanitation loan according to \\
MFIadministrative data and confirmed it during the \\
interview.
\end{tabular}

surveyor verified toilet ownership as the dependent variable. Importantly, this measure includes all toilets, regardless of whether they were functional, or were under construction. Column 1 of Table 5 indicates that the intervention led to a 9 percentage point increase in toilet ownership among study households. The estimate is robust to multiple hypothesis testing - both within the outcomes in the table, and across all outcomes considered in the paper (see Appendix C) - and corresponds to a 20 percent increase over the toilet ownership rate in the control group. Remarkably, this increase was achieved against a backdrop of increasing sanitation coverage in rural India, likely due to the SBM program: toilet ownership among clients in the control group increased from 24 percent in February 2015 to 45 percent by August 2017. Moreover, the estimated impact accounts for close to 40 percent of the increase in toilet ownership observed among clients in the treated communities over the study period. It is also within the range achieved by other sanitation interventions in other contexts. Studies considering impacts on the take-up of hygienic or improved toilets (as we do here) find impacts ranging from no impact from a latrine promotion program in Bangladesh studied by Guiteras et al. [2015] to a 19 percentage point increase from the Total Sanitation Campaign (which included a combination of awareness creation activities and subsidy provision) in Madhya Pradesh, India studied by Patil et al. $[2014] .^{21}$

Next, we measure whether sanitation loans were used for repair/upgrade in two ways: First, we study impacts on whether the household owns a functioning toilet - one that was not broken, or have a full pit - at the time of the endline survey and compare these estimates with those on toilet ownership. If loans were used to undertake toilet repairs that would otherwise not be undertaken, the impact on functioning toilets should be larger than that on toilet ownership. This difference thus allows us to capture the flow of sanitation investments into repairing existing toilets and/or preventing them from falling into disrepair. Second, we study impacts on toilet quality. If households used the loan to upgrade toilets, we should observe an improvement in the quality of the toilet. However, average intervention impacts on toilet quality will also capture the construction of higher-quality new toilets. Thus, in order to disentangle between the upgrading of existing toilets, and construction of higher quality toilets, we also study heterogeneity in impacts on toilet quality by baseline household toilet ownership. Improvements in the quality of toilets that existed at baseline would thus capture upgrade and repair work undertaken

\footnotetext{
${ }^{21}$ Other studies, including Pickering et al. [2015] and Clasen et al. [2014] report higher ( 30\%) impacts on the ownership of any toilet, which includes cheaper unimproved models that are not popular with households in our study area.
} 
Table 5: Intervention impact on toilet uptake (observed by interviewers)

\begin{tabular}{lcc}
\hline \hline & $(1)$ & $\begin{array}{c}(2) \\
\text { Functioning } \\
\text { toilet }\end{array}$ \\
\hline SL & $0.0899^{* * *}$ & $0.0927^{* * *}$ \\
& $(0.0244)$ & $(0.0233)$ \\
Cluster-robust p-value & {$[0.0002]$} & {$[0.0001]$} \\
Romano-Wolf p-value & {$[0.0000]$} & {$[0.0000]$} \\
Covariates & Yes & Yes \\
\hline Control mean & 0.413 & 0.376 \\
$\mathrm{~N}$ & 2821 & 2821 \\
\hline \hline
\end{tabular}

Notes: SL equals sanitation loan arm. Standard errors clustered at the village level are shown in parentheses. $*, * *, * * *$ indicate significance at the 10, 5 and 1 percent level, referring to RomanoWolf p-values. Covariates: See Table 3 Note. Functioning toilet is defined as toilet that is not broken, or does not have a full pit. Data source: household survey.

as a result of the intervention.

Column (2) in Table 5 shows that the intervention resulted in a 9.3 percentage point increase in the ownership of functioning toilets. This is only 0.3 percentage points higher than the impact on toilet ownership indicating that, in line with clients' own reports, few of the sanitation loans were used to rehabilitate existing toilets. ${ }^{22}$

Next, we consider the impacts of the intervention on the quality of toilets owned by households. The World Health Organisation and UNICEF encourage the construction of improved (or safe) sanitation facilities, which hygienically separate human excreta from human contact. Better quality toilets are more likely to remain functional, and are more likely to be used, facilitating sustained long-term changes in sanitation behaviour (Garn et al., 2017). The vast majority of toilets constructed in our context are safe toilets. Thus, we use a more detailed measure of quality, which, following consultations with sanitation experts in India and beyond, includes information on, among other dimensions, types of materials used to construct the underground chamber, ease of access, cross-ventilation, availability of a lockable door, availability of light.

We combine the recorded observations into summary measures for underground and overground quality using polychoric principal components analysis. The analysis yields one component for underground quality and two for overground quality. ${ }^{23}$ A detailed description of the approach, along with the loadings in the polychoric principal components analysis, is provided in Online Appendix C.

Table 6 displays the findings on these dimensions. The upper panel shows average impacts for the overall sample, while the lower panel shows the heterogeneous impacts by baseline toilet ownership. We obtain a small, positive average impact of the intervention on both components of overground

\footnotetext{
${ }^{22}$ This is also supported by examining impacts on functional toilet ownership among the sample of households with a toilet at baseline. We find a statistically significant impact of 2-3 percentage points. Thus, few loans were used to upgrade or repair toilets.

${ }^{23}$ The first component for overground quality captures good quality across all dimensions considered, while the second component captures good quality on a subset of variables only (quality of outside structure, distance between the pan and the wall, cross-ventilation, and availability of light).
} 
quality. However, it is not robust to multiple hypothesis testing. We also fail to detect any robust heterogeneous impacts on any dimension of toilet quality.

Table 6: Intervention impact on toilet quality

\begin{tabular}{|c|c|c|c|}
\hline & $\begin{array}{c}(1) \\
\text { Underground }\end{array}$ & $\begin{array}{c}(2) \\
\text { Overground } 1\end{array}$ & $\begin{array}{c}(3) \\
\text { Overground } 2\end{array}$ \\
\hline \multicolumn{4}{|c|}{ Panel A: Overall } \\
\hline SL & $\begin{array}{c}0.0140 \\
(0.0219)\end{array}$ & $\begin{array}{c}0.0631 \\
(0.0342)\end{array}$ & $\begin{array}{c}0.0519 \\
(0.0272)\end{array}$ \\
\hline Cluster-robust p-value & {$[0.5227]$} & {$[0.0653]$} & {$[0.0566]$} \\
\hline Romano-Wolf p-value & {$[0.5235]$} & {$[0.1528]$} & {$[0.1528]$} \\
\hline Covariates & Yes & Yes & Yes \\
\hline Control mean & 1.380 & 2.434 & 0.369 \\
\hline $\mathrm{N}$ & 1281 & 1281 & 1281 \\
\hline \multicolumn{4}{|c|}{ Panel B: By toilet ownership at baseline } \\
\hline SL - toilet at BL & $\begin{array}{l}0.00319 \\
(0.0286)\end{array}$ & $\begin{array}{c}0.0460 \\
(0.0463)\end{array}$ & $\begin{array}{c}0.0499 \\
(0.0306)\end{array}$ \\
\hline Cluster-robust p-value & {$[0.912]$} & {$[0.347]$} & {$[0.120]$} \\
\hline Romano-Wolf p-value & {$[0.912]$} & {$[0.688]$} & {$[0.42]$} \\
\hline SL - no toilet at BL & $\begin{array}{c}0.0276 \\
(0.0293)\end{array}$ & $\begin{array}{c}0.0847 \\
(0.0471)\end{array}$ & $\begin{array}{c}0.0545 \\
(0.0354)\end{array}$ \\
\hline Cluster-robust p-value & {$[0.329]$} & {$[0.069]$} & {$[0.124]$} \\
\hline Romano-Wolf p-value & {$[0.688]$} & {$[0.374]$} & {$[0.42]$} \\
\hline $\mathrm{HH}$ owns a toilet at BL & $\begin{array}{l}0.00192 \\
(0.0273)\end{array}$ & $\begin{array}{c}0.0666 \\
(0.0443)\end{array}$ & $\begin{array}{c}0.0161 \\
(0.0274)\end{array}$ \\
\hline Strata FE & Yes & Yes & Yes \\
\hline Interviewer FE & Yes & Yes & Yes \\
\hline Household covariates & Yes & Yes & Yes \\
\hline Ratio sample clients/GP size & Yes & Yes & Yes \\
\hline F-test & 0.522 & 0.545 & 0.902 \\
\hline Control Mean (toilet BL) & 1.392 & 2.438 & 0.346 \\
\hline Control Mean (no toilet BL) & 1.363 & 2.429 & 0.402 \\
\hline $\mathrm{N}$ & 1281 & 1281 & 1281 \\
\hline \multicolumn{4}{|c|}{$\begin{array}{l}\text { Notes: Sample of households owning a toilet at endline. SL equals sanitation loan } \\
\text { arm. Standard errors clustered at the village level are shown in parentheses. *, } \\
* *, * * * \text { indicate significance at the } 10,5 \text { and } 1 \text { percent level, referring to Romano- } \\
\text { Wolf p-values. Covariates: See Table } 3 \text { note. Dependent variable in Column } 1 \text { is } \\
\text { quality of underground chamber. That in Columns } 2-3 \text { is quality of overground } \\
\text { structure. Quality measures are computed using polychoric principal components } \\
\text { analysis. Data source: household survey. }\end{array}$} \\
\hline
\end{tabular}

These impact estimates thus indicate that the intervention supported new sanitation investments primarily in the form of new toilets, with repairs or upgrades playing only a small role. Using the intervention as an instrument for sanitation loans, we find that roughly $50 \%$ of sanitation loans were used to construct new toilets (see Table D.1 in Appendix D. ${ }^{24}$ An interesting question is whether the remaining loans simply displaced alternative funding sources for pre-planned sanitation investments, or whether they were diverted to some other purpose. While our design does not allow us to rigorously answer this question, two pieces of evidence indicate that a significant proportion of these loans were diverted to a non-sanitation purpose.

\footnotetext{
${ }^{24}$ This exercise assumes that changes in toilet ownership induced by the intervention happen only through the loan uptake, which would not hold if, for example, the intervention raised the salience of sanitation, which we rule out in this context in Section 6.
} 
First, as shown in Table 4, 16\% of clients reported using the sanitation loan for some non-sanitation purpose. We believe that this is a lower bound for loan diversion: if anything, clients have the incentive to lie and report using the loan for sanitation investments. Second, in line with this observation, we note that $26 \%$ of households that took a sanitation loan, and reported using it to construct a new toilet, already had a toilet prior to the intervention rollout. No household in our sample reported owning multiple toilets at endline. This observation, combined with the earlier analysis indicating that few loans were used to upgrade or repair toilets, suggests that these households most likely diverted the loan to a non-sanitation purpose. ${ }^{25}$

\subsection{Sanitation Usage}

In order for improved sanitation to reduce environmental contamination through open defecation, it is crucial that sanitation investments are accompanied by a change in sanitation behaviour. Put differently, it is essential that the toilets are used. Studies have documented, particularly in the Indian context, that households continue to defecate in the open despite owning a toilet (e.g. Barnard et al., 2013). We thus analyse the intervention impacts on self-reported open defecation practices in Table 7. Column (1) studies impacts on whether all household members engage in open defecation, while column (2) considers a broader definition of whether anyone in the household engages in open defecation. The estimates indicate a reduction of 10-11 percentage points in open defecation on both measures, which closely matches the impacts on toilet uptake, suggesting that households who construct a toilet also generally use it. ${ }^{26}$

To summarise, the analysis on the key outcomes indicates that intervention resulted in an increase in sanitation loan takeup, and that about every second loan led to the construction of a new toilet. However, not all sanitation loans resulted in new sanitation investments, with suggestive evidence that a significant proportion of the remaining loans were diverted to non-sanitation purposes. Finally, the results indicate that the new toilets are used, leading to a reduction in open defecation.

\footnotetext{
${ }^{25}$ An alternative way of assessing whether loans were diverted to non-sanitation purposes is to examine the impacts of the intervention on other investments and consumption expenditures. We did so for productive investments (likelihood of the household owning any type of business, an agricultural business (crop production and animal husbandry), whether a business closed, likelihood of having made a large business investment and reported profits) and consumption expenditures in the week prior to the endline survey. The results, displayed in Appendix Tables D.2 and D.3, indicate no statistically significant impacts on these outcomes. If anything, the coefficients are negative, though very small. However, this test is not conclusive for a number of reasons: First, the recall period for consumption expenditures (week prior to endline survey in August-September 2017) did not cover the period when most sanitation loans were disbursed (in 2015). Second, households might have diverted loans to other investments that were not captured in our data. Third, the average impacts reported might mask heterogeneity if, for instance, households making sanitation investments reduced other investments, which might net out, on average at least, any increased investments from those diverting the loan to another purpose. Finally, this analysis would not reveal any delays in making investments, which are likely in this context. Indeed, $58 \%$ of clients who reported forgoing another investment in order to take a sanitation loan reported having delayed making the investment.

${ }^{26}$ One concern with using self-reports is that households might under-report open defecation practices, and that those in the treated group might be more likely to do so than those in the control group. We believe that the latter - differential under-reporting by households in the treatment group - is unlikely to be the case in our context for two reasons: First, surveyor observations on the presence of cleaning materials in the toilet, and whether the path to the toilet looks trodden - which would indicate that the toilets are being used - are in line with the self reported usage measures: households with toilets typically use them. Second, households in this study use credit, which they have to repay, to construct a toilet. We believe these households are likely to have a higher motivation to use the toilet than the average rural Indian household.
} 
Table 7: Intervention impact on toilet usage

\begin{tabular}{|c|c|c|}
\hline & (1) & $(2)$ \\
\hline & \multicolumn{2}{|c|}{ Open Defecation } \\
\hline & $\begin{array}{l}\text { All HH } \\
\text { members }\end{array}$ & $\begin{array}{l}\text { Any HH } \\
\text { member }\end{array}$ \\
\hline SL & $\begin{array}{c}-0.108^{* * *} \\
(0.0252)\end{array}$ & $\begin{array}{c}-0.105^{* * *} \\
(0.0249)\end{array}$ \\
\hline Cluster-robust p-value & {$[0.0000]$} & {$[0.0000]$} \\
\hline Romano-Wolf p-value & {$[0.0000]$} & {$[0.0000]$} \\
\hline Covariates & Yes & Yes \\
\hline Control mean & 0.603 & 0.610 \\
\hline $\mathrm{N}$ & 2821 & 2821 \\
\hline \multicolumn{3}{|c|}{$\begin{array}{l}\text { Notes: SL equals sanitation loan arm. Standard errors clustered } \\
\text { at the village level are shown in parentheses. }{ }^{* *}, * * * \text { indicate } \\
\text { significance at the } 10,5 \text { and } 1 \text { percent level, referring to Romano- } \\
\text { Wolf p-values. Covariates: See Table } 3 \text { Note. HH stands for } \\
\text { household. Data source: household survey. }\end{array}$} \\
\hline
\end{tabular}

\section{Mechanisms}

An important question is what mechanisms underlie the intervention impacts. Answers to this questions are important not only for efficient design of policies and programs, but can also be informative about how observed impacts might translate to other settings. We specify a simple theoretical model of household borrowing and investment decisions to shed light on underlying mechanisms. A novel feature of the model is that we explicitly allow loan labels to influence household choices. Taking the predictions that this model generates to our data provides evidence that the loan label influences household investment decision making.. With this insight, the final sub-section explores reasons why the loan label influences household choices in this context.

\subsection{Theoretical Framework}

\subsubsection{General Model Set-up}

We consider a simple two-period framework in which a household receives an exogenous, uncertain endowment $(y)$ and chooses how much to spend on a consumption good (denoted $c$ ), and whether or not to invest in a toilet (denoted $s$ ) and/or a lumpy productive business investment (denoted $e$ ). Time is indexed by $t=\{1,2\}$. The endowment $y_{t}$ can take one of two values, $y \in\{h, l\}, h>l$; with $\operatorname{Pr}\left(y_{t}=h\right)=\pi$, where $0<\pi<1$. Expenditures on the consumption good are restricted to be non-negative in each period.

The prices of the toilet and business investment are $p_{s}$ and $p_{e}$ respectively, while the price of the consumption good is normalised to 1 . For simplicity, households can invest in at most one unit each of the toilet, and business investment. No household in our data reports owning more than one toilet, making this a reasonable assumption for toilet investments in this context. Owning a toilet yields a return of $\gamma$, which captures both the monetary gains (e.g. reduced health expenditures due to better health) and the monetary value of (non-monetary) benefits such as improved convenience and safety. 
The business investment yields a return of $\theta$. The returns to both goods are non-stochastic and accrue in the period after the investments are made. The time gap between making the investment decision and when the returns are realised capture the time needed to 'build' the investment.

The household cannot save, but has access to some labelled loans. Initially, prior to the intervention roll-out, it can borrow a (labelled) business loan, denoted $b_{e}$, at an interest rate of $r_{e} ; 0<r_{e}<1$, with a maximum amount of $b_{e}^{\max }$. Later, a (labelled) sanitation loan, denoted $b_{s}$ is made available to households at an interest rate of $r_{s} ; 0<r_{s}<1$. In line with the intervention evaluated, we allow $r_{s}<r_{e}$. We assume that households face a sufficiently large penalty from defaulting on a loan, so that at the optimum, the household will not default.

Loan Labels: A novel feature of the model is to allow households to be sensitive to loan labels, which could influence borrowing and investment decisions for a number of reasons: first, households might believe (correctly or incorrectly) that the lender will punish loan misuse by preventing access to future loans. Relatedly, they may (potentially incorrectly) believe that appropriate loan use, similar to high repayment rates, will enhance their reputation with the lender leading to continued access to finance and potentially larger and cheaper loans in the future. Second, individuals might use mental accounts to manage their finances, and may assign sources of money to different expenditures according to associated labels (Thaler, 1999). A (labelled) business loan would thus be earmarked for the business investment, and would be unavailable for other expenditures. Finally, individuals may have an aversion to dishonesty, and thus take the labelled loan only if they plan to make the related investment (Gneezy, 2005; Abeler et al., 2014; Abeler et al., Forthcoming).

Households might thus experience a disutility if they take a labelled loan and divert it to some other purpose. We thus model households' sensitivity to loan labels as a disutility, denoted by $\kappa$, experienced in the period when the loan is taken, if a labelled loan is diverted to another purpose. We allow the disutility to increase with loan size. A household that borrows $b_{e}$ that is diverted away from a business investment will face a disutility $\kappa b_{e}$, where $\kappa \geq 0 . \kappa=0$ when the household is insensitive to the loan label. ${ }^{27}$ This formulation is similar to Benabou and Tirole [2004], Koch and Nafziger [2016] and Hastings and Shapiro [2018].

We impose some conditions on the sizes of $p_{s}, p_{e}, h, l$ and $b_{e}^{\max }$, to ensure that the household will need to borrow in order to make both investments, and depending on the period 1 endowment realisation, any investment. These conditions are laid out formally in Assumption 1.

Assumption 1. (i) $p_{s}+p_{e}>b_{e}^{\max }$; (ii) $l<p_{e}<h$ and $l<p_{s}<h$; and (iii) $p_{e}+p_{s}>h$

The first part of the assumption rules out the ability to make both investments by simply taking the business loan, while the second implies that the household would be unable to make any investment

\footnotetext{
${ }^{27}$ In addition, the loan label could convey information about the importance of the labelled investment, or raise its salience. This formulation does not capture these effects of the label. The model could be easily extended to incorporate this channel, by allowing households to have incorrect beliefs about investment returns, which the presense of the labelled loan would induce them to update. Were salience or information the only channel through which the sanitation loan label works, simply offering the sanitation loan could increase sanitation investment without requiring sanitation loan take-up. Our results rule this out; while evidence presented in Section 6.2 offers further, more complete evidence ruling out this channel.
} 
from its endowment only if $y_{1}=l$. If $y_{1}=h$, it can make one of the two investments without needing to borrow. The third part of the assumption, rules out that households with $y_{1}=h$ could make both investments without borrowing. This assumption thus ensures that there is demand for borrowing.

The household has linear utility - gained from the consumption good, net of disutilities from loan diversion - and discounts period 2 utility with the discount factor $\beta, 0<\beta<1$. It makes decisions in the following sequence. In period 1 , it learns its endowment realisation, $y_{1}$, and makes its borrowing, consumption $\left(c_{1}\right)$ and investment choices. In period 2, the realisation of $y_{2}$ is realised. This along with the investment returns allows it to repay loans and fund consumption, $c_{2}$.

Prior to the introduction of the sanitation labelled loan, a household which takes a business loan to invest in a toilet only would achieve the payoff:

$$
E U(e=0, s=1)=y_{1}+b_{e, y_{1}}^{01}-p_{s}-\kappa b_{e, y_{1}}^{01}+\beta E\left(y_{2}+\gamma-\left(1+r_{e}\right) b_{e, y_{1}}^{01}\right)
$$

where $b_{e, y_{1}}^{01}$ is the amount of the business loan taken to invest in the toilet only for a household drawing an endowment of $y_{1}$. By contrast, the payoff from taking a business loan to make a business investment only would be:

$$
E U(e=1, s=0)=y_{1}-p_{e}+b_{e, y_{1}}^{10}+\beta E\left(y_{2}+\theta-\left(1+r_{e}\right) b_{e, y_{1}}^{10}\right)
$$

where $b_{e, y_{1}}^{10}$ is the amount of the business loan taken when the draws an endowment of $y_{1}$. Thus, the loan diversion penalty makes the toilet investment relatively less attractive to make in the absence of a sanitation loan.

The households in our economy are heterogeneous in $\kappa, \gamma$ and $\theta$. The heterogeneity in $\kappa$ offers one explanation for why some households take the sanitation loan for non-sanitation purposes. Households are otherwise identical: they have the same utility function, face the same prices, $p_{s}$ and $p_{e}$, and the same income process.

\subsubsection{Theoretical Results}

We now present four propositions. The first characterises how sensitivity to loan labels affects household borrowing and investment decisions, and how the introduction of the sanitation labelled loan will impact sanitation investments.

Proposition 1. When $\kappa=0$ and prior to the introduction of the sanitation labelled loan, households will make sanitation investments as long as $\beta \gamma \geq p_{s}$ even if they need to borrow to do so. If the household is liquidity constrained and can make only one investment, it will invest in sanitation if, in addition, $\beta(\gamma-\theta)>\left(p_{s}-p_{e}\right)$. However, when $\kappa>0$, households that need to borrow to make any investment will make sanitation investments only when $\beta \gamma \geq p_{s}+\kappa b_{e, y_{1}}^{01}$. Liquidity constrained households that can make only one investment will invest in sanitation if, in addition, $\beta(\gamma-\theta)>\left(p_{s}+\kappa b_{e, y_{1}}^{01}-p_{e}\right)$. The introduction of a sanitation labelled loan will lead to an increase in sanitation investments, with larger increases among households with $\kappa>0$. 
Proof. The proof of this proposition follows from the consideration of the expected utilities associated with making the sanitation investment only, relative to making no investment, or making the business investment only (for liquidity constrained households) when $\kappa=0$ and $\kappa>0$.

The key implication of this proposition is that when households are sensitive to loan labels, their investment decisions will be skewed towards those for which labelled loans are available. Thus, the availability of only the business labelled loan will depress sanitation investments. Consequently, when a sanitation labelled loan with similar conditions (e.g. interest rate) as the business labelled loan is introduced, the sanitation loan will be taken and sanitation investments will increase. The increase will be larger among households with $\kappa>0$, who were under-investing in sanitation.

However, the sanitation loan program we evaluate offered the sanitation labelled loans at a lower interest rate relative to the business loan. The lower interest rate could also in itself encourage sanitation investments by reducing its cost to households. Moreover, the lower interest rate might also make the sanitation loan more attractive, particularly for households that are not very sensitive to loan labels. The next propositions thus lay out the effects of the lower interest rate on investment choices (Proposition 2) and borrowing (Proposition 3). As we will see, the latter offers an empirically testable prediction to identify whether study households' behaviour is driven by sensitivity to loan labels.

Proposition 2. The lower interest rate reduces the cost of making investments. There exists a label sensitivity threshold, $\kappa^{*}=\beta\left(r_{e}-r_{s}\right)$ such that for households with $\kappa<\kappa^{*}$, either investment can now be made at a lower cost, resulting in an increase in both sanitation and business investments. By contrast, for households with $\kappa \geq \kappa^{*}$ and that need to borrow to make any investment, the lower interest rate will reduce the cost of sanitation investments only, especially when they only invest in one good. Thus compared to households with $\kappa<\kappa^{*}$, the lower interest sanitation loan will lead to a larger increase in sanitation investments.

Proof. See Appendix E.

Proposition 3. When $r_{e}>r_{s}$, households with $\kappa<\kappa^{*}$ will substitute away from the business loan to the sanitation loan, regardless of their investment choices. By contrast, households with $\kappa \geq \kappa^{*}$ will take the sanitation loan only if they intend to make a sanitation investment.

Proof. See Appendix E.

Proposition 3 indicates that the increases in sanitation investments seen could also be driven by the lower interest rate. Proposition 3 offers an empirically testable prediction that allows us to identify whether study households' behaviour is driven by sensitivity to loan labels: if all households in our context are insensitive to loan labels, they should all take advantage of the lower interest rate on the sanitation loan and substitute away from the business loan regardless of their investment choices. We consider this formally in section 6.2 . 
The sanitation loan also increased the supply of credit in the economy. This could also influence investments by relaxing liquidity constraints. If this is the case, the increased investments should be accompanied by increased overall borrowing, as outlined in Proposition 4 below.

Proposition 4. Overall borrowing must increase if the sanitation loan relaxes overall liquidity constraints, thereby allowing new investments to be made. It will also increase if the lower interest rate encourages new investments. It will not increase if either (i) $\kappa<\kappa^{*}$ and households substitute to the lower interest sanitation loan without changing investment decisions, or (ii) $\kappa>\kappa^{*}$ and the household remains liquidity constrained. In this case, take-up of a specific labelled loan and investment would be accompanied by substitution away from other labelled loans and investments.

Proof. See Appendix E.

Proposition 4 also offers another test for whether loan labels influenced household choices in our study. In particular, it indicates that when $\kappa>\kappa^{*}$, the increased sanitation investment should be accompanied by either an increase in overall borrowing, or no increase in borrowing (if the household is still liquidity constrained), but substitution away from other labelled loans and investments. When $\kappa<\kappa^{*}$, by contrast, the increased sanitation investment must always be accompanied by an increase in overall borrowing. Thus, borrowing behaviour can also provide insight into the influence of loan labels.

\subsection{Empirical evidence on the role of the loan label}

Drawing on Propositions 3 and 4 in the model, we consider three margins of borrowing behaviour, to test whether loan labels influenced households' responses to the sanitation loan intervention. First, in line with Proposition 3, we investigate whether or not households substituted away from more expensive loans to the cheaper sanitation loan when it was introduced. Households with $\kappa>\kappa^{*}$ will not substitute to the sanitation loan unless they intend to make a sanitation investment. Second, we investigate the intervention's impacts on overall household borrowing. Third, we study whether households substituted away from other labelled loans with similar or even lower interest rates. Studying impacts on the latter two margins is motivated by Proposition 4.

We start by studying borrowing choices using the MFI's administrative data, which has accurate information on the interest rates for all loans disbursed. Table 8 displays the impacts of the intervention on the amounts borrowed of different types of loans over the course of the study period. Business loans from the MFI had consistently higher interest rates than sanitation loans. However, while the table indicates a statistically significant increase in sanitation loan borrowing, it does not display any evidence of substitution away from more expensive business loans. ${ }^{28}$ In fact, the coefficient is positive, though not statistically significantly different from 0, indicating a potential increase.

Descriptive analysis of the data provides further support for the conclusion that a significant proportion of households did not substitute away from more expensive loans to the cheaper sanitation loan when

\footnotetext{
${ }^{28}$ The vast majority of business loans disbursed to study clients had a 2-year tenure.
} 
Table 8: Intervention impact on uptake of loan products from the MFI (amount borrowed)

\begin{tabular}{lccccc}
\hline \hline & $(1)$ & $(2)$ & $(3)$ & $(4)$ & $(5)$ \\
& Sanitation & Business & Education & Emergency & Consumption \\
\hline SL & $2654.4^{* * *}$ & 988.0 & -477.3 & 107.3 & 46.89 \\
& $(527.4)$ & $(2252.9)$ & $(871.5)$ & $(143.8)$ & $(99.66)$ \\
Cluster-robust p-value & {$[0.0000]$} & {$[0.6610]$} & {$[0.5840]$} & {$[0.4559]$} & {$[0.6381]$} \\
Romano-Wolf p-value & {$[0.0000]$} & {$[0.8941]$} & {$[0.8941]$} & {$[0.8661]$} & {$[0.8941]$} \\
Covariates & Yes & Yes & Yes & Yes & Yes \\
\hline Control mean & 199.9 & 37871.2 & 8314.7 & 699.9 & 362.9 \\
N & 2821 & 2821 & 2821 & 2821 & 2821 \\
\hline \hline
\end{tabular}

Notes: SL equals sanitation loan arm. Standard errors clustered at the village level are shown in parentheses. $*, * *, * * *$ indicate significance at the 10,5 and 1 percent level, referring to Romano-Wolf p-values. Covariates: See Table 3 note. Amounts are in Indian Rupees (1 USD = INR 67.5). Data sources: MFI administrative data (dependent variable) and household survey (covariates).

it was introduced. Among treatment GPs, the data indicates that $78.3 \%$ of clients took a new loan from the MFI over the study period. Remarkably, $73.3 \%$ of these clients took a more expensive 2-year business loan rather than the cheaper sanitation loan despite being eligible to take a sanitation loan. Here, 'more expensive' is defined along two margins: the interest rate, and the the (weekly) installment amounts. The latter is of particular relevance given it is generally understood (and confirmed by our implementing partner) that clients pay close attention to the instalment size when making loan take-up decisions. The installment amount of a 2-year sanitation loan on INR 15,000 ranged between INR 173 and 179 over the course of the experiment, compared with between INR 180 - 184 for a similar sized 2-year business loan. ${ }^{29}$

Households, could of course have been attracted by the larger loan size offered by business loans. However, we note that they faced no restriction in taking a sanitation loan in parallel with other loans. Theory would then suggest that if loan labels do not matter, households should take more expensive loans only after they exhaust the limit on sanitation loans. The data indicates, though, that a significant proportion of clients do not optimise their borrowing portfolio in this manner: 31 percent of clients in treated areas took a business loan of over INR 25,000 (the lowest amount that can be taken as separate sanitation and business loans) even when they were eligible for a sanitation loan. This evidence is consistent with households being sensitive to loan labels. ${ }^{30}$

Next, we study impacts on overall household borrowing. We use data from the endline household survey, which - as is common - asked households about the three largest loans (above INR 500) taken

\footnotetext{
${ }^{29}$ While the differences in installment amounts might appear to be relatively small, these are non-negligible for households in our setting. Around $16.5 \%$ of households in the control group report having been unable to obtain sufficient food in the 8 months prior to the endline survey. Taking the cheaper sanitation loan rather than a business loan saves roughly INR 20 per month in extra interest payments, allowing households to purchase an additional $1 \mathrm{~kg}$ of wheat, or $600 \mathrm{~g}$ of rice from a non-Government shop.

${ }^{30}$ Over $80 \%$ of clients who did not take a sanitation loan in the treatment areas report not having considered doing so, providing further evidence that the clients did not simply consider interest rates when making loan choices.
} 
since the start of the experiment. ${ }^{31,32}$ In addition to information such as loan size and outstanding balance, respondents were asked to report on the lending source, which we use to classify loans into two categories - formal and informal. ${ }^{33}$ The former is further split between MFI borrowing and other formal sources. Table 9 presents the impact estimates on the different dimensions of borrowing.

We find that the sanitation loan uptake is not accompanied by any increase in overall borrowing, on average. In fact, the coefficient is negative, and statistically insignificant. When we look at the breakdown of borrowing from different sources, we observe a positive but statistically insignificant coefficient on microfinance borrowing, accompanied by negative coefficients (though statistically insignificant) on borrowing from other formal and informal sources. Thus, this evidence indicates that overall borrowing did not increase.

Table 9: Intervention impact on household borrowing - total, formal and informal sources

\begin{tabular}{lccccc}
\hline \hline & $(1)$ & $(2)$ & $(3)$ & $(4)$ & $(5)$ \\
& Total & Formal & MFIs & Other formal & Informal \\
\hline SL & -465.3 & -99.14 & 336.5 & -435.6 & -366.1 \\
& $(1845.8)$ & $(1877.3)$ & $(1533.1)$ & $(1578.3)$ & $(399.8)$ \\
Cluster-robust p-value & {$[0.8010]$} & {$[0.9579]$} & {$[0.8263]$} & {$[0.7826]$} & {$[0.3599]$} \\
Romano-Wolf p-value & {$[0.9700]$} & {$[0.9700]$} & {$[0.9700]$} & {$[0.9700]$} & {$[0.7662]$} \\
Covariates & Yes & Yes & Yes & Yes & Yes \\
\hline Control mean & 31744.3 & 29379.7 & 14969.7 & 14409.9 & 2364.6 \\
N & 2793 & 2793 & 2793 & 2793 & 2793 \\
\hline \hline
\end{tabular}

Notes: SL equals sanitation loan arm. Standard errors clustered at the village level are shown in parentheses. $*, * *, * * *$ indicate significance at the 10, 5 and 1 percent level, referring to Romano-Wolf p-values. Covariates: See Table 3 Notes. Amounts are in Indian Rupees (1 USD = INR 67.5). To remove the influence of outliers in the dependent variable, we drop households in the top 1 percent of the distribution of total borrowing. Data source: household survey.

Proposition 4 indicates that overall borrowing might not increase in two cases - either if $\kappa<\kappa^{*}$ and households substitute toward the cheaper sanitation loan without changing their investment decisions, or if $\kappa>\kappa^{*}$ and households remain liquidity constrained. In the latter case, they would substitute away from other labelled loans and investments.

The first of these possible explanations can be ruled out for three reasons: First, as shown in Section

\footnotetext{
${ }^{31}$ Furthermore, respondents were asked about three small loans taken in the month prior to the survey. We do not use these data in our analysis since this was collected for the month prior to the survey, rather than since the start of the intervention. Extrapolating the responses to the whole study period requires extremely strong and implausible assumptions (e.g. that the borrowing in the past month is representative of the whole period). Moreover, it is very unlikely that households would be able to aggregate sufficient loans of this size $(<$ INR 500) to invest in a toilet.

${ }^{32} \mathrm{By}$ focusing on the three largest loans, there is a risk of under-reporting of borrowing due to censoring, and/or misreporting by households. If treated households took more loans as a result of the intervention, the former could bias downward any impact estimate. We compare responses on microfinance borrowing in the household survey data with credit bureau data on microfinance borrowing, and find significant underreporting of microfinance borrowing (the average control group household reported less than $20 \%$ of actual microfinance borrowing) that is balanced across treatment groups. Gross and Souleles [2002] and Karlan and Zinman [2008] also document such underreporting for US credit card debt and microfinance borrowing in the Philippines. It is unlikely that the underreporting is driven by recall error or survey design: households were not less likely to report on loans taken early in the study period, and there were no differences in the number of loans reported in the household survey by treatment status (Online Appendix E). Moreover, any underreporting due to censoring is likely to be small: Just over $20 \%$ of households, balanced by treatment status, reported taking three loans. Reassuringly, when we estimate intervention impacts on microfinance borrowing using the credit bureau data, we find, similar to the household survey data presented here: a small positive, but statistically insignificant coefficient.

${ }^{33}$ We classify as formal sources banks, MFIs, NGOs, cooperatives/savings funds, and Self Help Groups (SHGs). Informal sources are moneylenders, relatives, friend/acquaintance/private financiers, work, pawnshop and other local shops.
} 
5 , the sanitation loan intervention led to an increase in new sanitation investments, with no significant reductions in business investments. Second, the evidence presented in Table 8 indicates that households did not, on average, substitute away from more expensive business loans towards the cheaper sanitation loan in the treatment GPs. Finally, additional descriptive evidence further indicates that the vast majority of households - over $73 \%$ of those who took a new loan from the MFI over the study period - took a more expensive 2-year business loan rather than a cheaper sanitation loan.

In the absence of direct measures of $\kappa$, it is not possible to test whether the second case holds. However, we provide evidence that this is the case, by showing first that the sanitation loan program did not fully alleviate liquidity constraints for all households; and second, that some households (at least) substituted away from other labelled loans to the sanitation loan. Two pieces of evidence indicate that liquidity constraints were not fully alleviated for all households. First, the maximum sanitation loan did not fully cover the cost of toilets study households want to construct. Control households report spending INR 25,000 on average; and indeed $54 \%$ of clients who took a sanitation loan reported that supplementary funds were required to cover toilet construction costs. The supplementary funds came from savings (45\% of loan-takers) and informal loans from friends and family (11\% of loan-takers).

Second, as shown in Table 10, we find that households with liquid savings at baseline were more likely to convert the sanitation loan to a new toilet, even though they were similarly or even slightly less likely to take a sanitation loan in the first place. Indeed, while all sanitation loans taken by households with savings at baseline result in a new toilet, only around one third of loans taken by households without savings at baseline result in a new toilet. This evidence suggests that the sanitation loan program did not fully relax households' liquidity constraints.

Table 10: Heterogeneous impacts by household savings at baseline

\begin{tabular}{lcc}
\hline \hline & $\begin{array}{c}(1) \\
\text { Sanitation } \\
\text { loan }\end{array}$ & Own toilet \\
\hline SL - savings & $0.164^{* * *}$ & $0.179^{* * *}$ \\
& $(0.0481)$ & $(0.0453)$ \\
Cluster-robust p-value & {$[0.007]$} & {$[0.002]$} \\
Romano-Wolf p-value & {$[0.007]$} & {$[0.005]$} \\
SL - no savings & $0.201^{* * *}$ & 0.0477 \\
Cluster-robust p-value & $(0.0359)$ & $(0.0326)$ \\
Romano-Wolf p-value & {$[0.001]$} & {$[0.141]$} \\
HH had savings at BL & {$[0.001]$} & {$[0.141]$} \\
Covariates & 0.0142 & $-0.0707^{* *}$ \\
F-test & $(0.0189)$ & $(0.0351)$ \\
Control mean (No savings) & Yes & Yes \\
Control mean (Savings) & 0.369 & 0.0107 \\
N & 0.0213 & 0.428 \\
\hline \hline Notes: SL equals sanitation loan arm. Standard errors clustered \\
at the village level are shown in parentheses. * **, *** indicate \\
significance at the 10, 5 and 1 percent level, referring to Romano- \\
Wolf p-values. Covariates: See Table 3 Note. & Data source: \\
household survey and administrative data. & \\
& 1113 & 0.440 \\
\end{tabular}


Further, Table 8 provides suggestive evidence (though not statistically significant at conventional levels) of some substitution away on average from education loans provided by the implementing MFI towards the sanitation loan in the treated GPs. ${ }^{34}$ Interestingly, education loans have the same interest rate as the sanitation loan, ruling out that the substitution is driven by this factor. ${ }^{35}$

Combined, these pieces of evidence provide support for the hypothesis that loan labels influenced households' borrowing and investment decisions. An interesting question is how loan labels influence household behaviour, which we turn to next.

\subsection{Discussion}

The empirical evidence provides support for the hypothesis that the loan label influenced households' borrowing and investment decisions, and through this generated the observed impacts on sanitation investments. An interesting question relates to how loan labels influence these decisions. Economic theory suggests a number of channels including mental accounting, information and salience, and perceived enforcement of loan use and reputation building.

Mental accounting We argue that mental accounting is the key channel through which loan labels influence household choices in this context. Mental accounting refers to the set of cognitive operations used by households to categorise funds and expenditures to different groups in order to keep track of financial activities (Thaler, 1999; Henderson and Peterson, 1992). Such a categorisation is understood to facilitate the processing of information necessary to evaluate spending opportunities (Zhang and Sussman, 2004), thus reducing the cognitive effort required to evaluate the decision at hand (Henderson and Peterson, 1992). Although boundaries of mental accounts are only notional, and hence should not bear on the decision-making of an economic agent, there is vast evidence that how funds are grouped and labelled influences individuals' financial decisions, thereby violating the economic principle of fungibility (Shefrin and Thaler, 1988, Thaler, 1990, 1999, Abeler and Marklein, 2017).

Labelling has been shown to be effective in protecting savings and remittances from being siphoned off to other purposes (De Arcangelis et al., 2015;Karlan and Linden, 2018) thereby helping individuals maintain financial discipline (Shefrin and Thaler, 1988). A similar rationale underlies the choice of the implementing MFI - which, in addition to a financial objective, has a social objective - to offer loans labelled for different purposes. More generally, to the best of our knowledge, unlabelled loans are hardly (if ever) used in microfinance. For instance, one of the very first MFIs, Grameen Bank, started by offering business loans, intending the loans to be used to fund income generating activities, which would enable borrowers to re-pay the loans.

\footnotetext{
${ }^{34}$ The lack of statistical significance comes from the fact that this substitution is concentrated among a sub-group of households: Augsburg et al. [2019] show clear evidence of such substitution among households who were ineligible for the subsidy from SBM.

${ }^{35}$ Without detailed information on education investments around the time the sanitation loans were taken, we are unable to investigate whether households substituted away from educational investments. Clients reports indicate that among those who reported forgoing another investment (20\% of sanitation loan-takers), the majority (58\%) delayed other investments, rather than scrapped them.
} 
Table 11: Impacts on perceived benefits and costs of a double-pit toilet (combined score of six dimensions)

\begin{tabular}{lccc}
\hline \hline & $\begin{array}{c}(1) \\
\text { Benefits }\end{array}$ & $\begin{array}{c}(2) \\
\text { Costs - } \\
\text { comp.1 }\end{array}$ & $\begin{array}{c}(3) \\
\text { Costs - } \\
\text { comp.2 }\end{array}$ \\
\hline SL & 0.00837 & 0.0534 & -0.00967 \\
Cluster-robust p-value & $(0.0488)$ & $(0.0973)$ & $(0.0436)$ \\
Romano-Wolf p-value & {$[0.8640]$} & {$[0.5834]$} & {$[0.8248]$} \\
Covariates & {$[0.9710]$} & {$[0.9231]$} & {$[0.9710]$} \\
\hline Control mean & Yes & Yes & Yes \\
$\mathrm{N}$ & 10.88 & 6.869 & -0.557 \\
\hline \hline Notes: Sample of households asked about a twin pit toilet: & 2,723 house- \\
holds. SL refers to sanitation loan treatment arm. Standard errors clus- & 2723 \\
tered at the village level shown in parentheses. *, **, *** indicate signifi- \\
cance at the 10, 5 and 1 percent level, referring to Romano-Wolf p-values. \\
Covariates: See Table 3 notes. Dimensions considered for benefit score: \\
improved health and safety for women, household status, and happiness, \\
increases in labour supply and time saving. Dimensions considered for cost \\
score: toilet unhealthiness, missing time with others, getting sick more eas- \\
ily, spending more time fetching water, difficulty and cost of emptying the \\
pit.
\end{tabular}

Unfortunately, we are unable to directly test for mental accounting in our data. However, we argue that this is the most likely explanation by ruling out other possibilities.

Information/Salience A first alternative explanation is that the availability of a sanitation loan from a well reputed MFI signalled the importance of sanitation. If this were the case, we would expect clients in the treated communities to be better informed about the costs and benefits of safe sanitation. We use novel data on perceptions of the costs and benefits of safe sanitation of a standardised toilet for a typical household in their village to test the relevance of this explanation. ${ }^{36}$ Client households were asked about the degree to which they agreed or disagreed with statements capturing perceived costs and benefits, including improved safety for women, increased household status, and difficulties in emptying the toilet pit when full.

Constructing summary measures of perceived costs and benefits using polychoric principal components analysis, we find in Table 11 that the intervention did not change perceptions of costs or benefits of sanitation, indicating that the intervention did not increase the salience of sanitation.

Perceived enforcement/reputation building Second, and specific to microcredit, the loan label could have influenced household choices through (perceived) enforcement of loan use and reputation building. Microfinance programs are often characterised by progressive lending, where timely repayment is rewarded with larger loans at possibly lower interest rates. Such rewards are considered to be an important driver of the high repayment rates of MFIs (Morduch, 1999). It is possible that this

\footnotetext{
${ }^{36} \mathrm{~A}$ small number of clients, mainly in the control GPs, were asked about another toilet. We drop these households from the analysis. Attanasio et al. [2018] shows that the sample is balanced between treatment and control for households shown the picture of the twin pit toilet.
} 
distinguishing feature of microfinance might be internalised by clients and projected onto loan use as well. Thus, while loan use is not enforced and diversion does not carry any official sanction, clients (and possibly their joint liability groups) might perceive that deviating from the intended (labelled) investment will be punished by the MFI. Conversely, good behaviour - using the loans as intended could be perceived as a means of positively influencing future loan application decisions to the MFI.

We take two approaches to study the relevance of this explanation. First, we construct a proxy for the level of enforcement, and analyse sanitation loan uptake and conversion under high and low enforcement conditions. The proxy we use is the degree to which members of the lending centre a client belongs to have been able to take an education loan - meant to support child schooling investments - from the implementing MFI despite not having children aged 6-18 years in the household. A lending centre is defined as having low (high) enforcement if the proportion of clients that obtained an education loan despite not having children in the eligible age range is greater (lower) than the sample median. We hypothesize that when the likelihood of receiving an education loan despite not having any children is high, perceived enforcement is likely to be low, leading to higher sanitation loan uptake and, importantly, lower loan-to-new toilet conversion. We estimate heterogeneous impacts of the intervention on sanitation loan uptake and toilet ownership along these margins, finding in Table 12 that households in low-enforcement treated GPs were statistically significantly (at the $10 \%$ level) more likely to take the sanitation loan. However, as shown in the bottom of the table, the use of sanitation loans for the construction of new toilets, and hence the loan-to-new-toilet conversion rates, do not differ significantly by enforcement level. The results therefore do not lend support to the idea that the label works through perceived loan enforcement.

Table 12: Heterogeneous impacts by level of enforcement

\begin{tabular}{lcc}
\hline \hline & $(1)$ & $(2)$ \\
& $\begin{array}{c}\text { Sanitation } \\
\text { loan }\end{array}$ & Own toilet \\
\hline SL - High enforcement & $0.105^{*}$ & 0.0494 \\
& $(0.0453)$ & $(0.0354)$ \\
Cluster-robust p-value & {$[0.047]$} & {$[0.188]$} \\
Romano-Wolf p-value & {$[0.077]$} & {$[0.188]$} \\
SL - Low enforcement & $0.231^{* * *}$ & $0.119^{* * *}$ \\
& $(0.0526)$ & $(0.0320)$ \\
Cluster-robust p-value & {$[0.005]$} & {$[0.006]$} \\
Romano-Wolf p-value & {$[0.002]$} & {$[0.008]$} \\
High enforcement & $0.0992^{* * *}$ & 0.0433 \\
& $(0.0332)$ & $(0.0326)$ \\
Covariates & Yes & Yes \\
\hline F-test & 0.0928 & 0.137 \\
Control Mean (High enforcement) & 0.0214 & 0.392 \\
Control Mean (Low enforcement) & 0.00826 & 0.426 \\
Loan-to-toilet conversion (High enforcement) & & $0.482^{*}$ \\
Loan-to-toilet conversion (Low enforcement) & & $0.515^{* * *}$ \\
N & 2821 & 2821 \\
\hline \hline Notes: SL equals sanitation loan arm. Standard errors clustered at the village \\
level are shown in parentheses. ${ }^{* * *}$, $^{* * *}$ indicate significance at the 10,5 and 1 \\
percent level, referring to Romano-Wolf p-values. Covariates: See Table 3 Note. \\
Data source: household survey and administrative data. & \\
& &
\end{tabular}


Table 13: Heterogeneous impacts by membership length

\begin{tabular}{lcc}
\hline \hline & $(1)$ & $(2)$ \\
& $\begin{array}{c}\text { Sanitation } \\
\text { loan }\end{array}$ & Own toilet \\
\hline SL - Short membership & $0.242^{* * *}$ & $0.104^{* * *}$ \\
& $(0.0495)$ & $(0.0339)$ \\
Cluster-robust p-value & {$[0.002]$} & {$[0.003]$} \\
Romano-Wolf p-value & {$[0.002]$} & {$[0.01]$} \\
SL - Long membership & $0.139^{* * *}$ & $0.0723^{* *}$ \\
& $(0.0363)$ & $(0.0325)$ \\
Cluster-robust p-value & {$[0.005]$} & {$[0.036]$} \\
Romano-Wolf p-value & {$[0.006]$} & {$[0.036]$} \\
Long membership & -0.0206 & 0.0375 \\
& $(0.0217)$ & $(0.0239)$ \\
Covariates & Yes & Yes \\
\hline F-test & 0.0413 & 0.452 \\
Control Mean (Short membership) & 0.0228 & 0.356 \\
Control Mean (Long membership) & 0.00571 & 0.481 \\
Loan-to-toilet conversion (Short membership) & & $0.430^{* * *}$ \\
Loan-to-toilet conversion (Long membership) & & $0.526^{* *}$ \\
N & 2496 & 2496 \\
\hline \hline Notes: SL equals sanitation loan arm. Standard errors clustered at the village \\
level are shown in parentheses. ${ }^{* * *}, * * *$ indicate significance at the 10,5 and 1 \\
percent level, referring to Romano-Wolf p-values. Covariates: See Table 3 Note. \\
Data source: household survey and administrative data. & \\
& &
\end{tabular}

Second, we consider whether clients' behaviour is consistent with reputation building by testing whether sanitation loan take-up and investment behaviour vary with the length of time the client has been a member of the implementing MFI. Longer standing clients of the MFI should have less of a need to prove themselves, and should thus be more likely to take the sanitation loan for a non-sanitation purpose. Estimating heterogeneous treatment effects by length of membership (above and below sample median 19 months), we find in Table 13 that sanitation loan uptake is significantly higher among newer clients. However, a smaller proportion of these loans are converted into new toilets (43\% vs 57\%), resulting in similar increases in toilet ownership for the two groups of clients. This finding is contrary to what we would expect if clients were trying to build their reputation with the MFI.

We conclude from this analsysis that our data does not lend support to the idea that the label influenced household choices because of either perceived enforcement of loan use, or reputation building with the MFI. Thus, mental accounting remains the most likely explanation for why loan labels matter in this context.

\section{Conclusion}

This paper provides, to our knowledge, the first rigorous evidence on the effects of labelled microcredit on the adoption of an important lumpy preventive health investment - a household toilet. Drawing on a cluster randomised controlled trial in rural Maharashtra, India, and rich data from a primary household survey and two novel sources of administrative data, we show that providing joint-liability 
credit labelled for sanitation is an effective approach to motivate toilet construction. Two and a half years after intervention rollout, 18 percent of eligible clients had taken a sanitation loan, resulting in a 9 percentage point increase in toilet ownership, and a 10 percentage point reduction in open defecation.

Through a simple theoretical framework and supporting evidence from our data, we show that it is not just the provision of credit that matters, but that credit attributes are important. While this is a wellestablished finding in terms of for example collateral ([Jack et al., 2017]), liability structure ([Attanasio et al., 2015b]), and grace period ([Field et al., 2013]), the novelty of this study is to show that the label itself plays a significant role in affecting loan uptake and investment decisions of poor households. Two key implications of the model allow us to establish this. First, sensitivity to loan labels can distort household borrowing decisions, so that they do not take cheaper labelled loans unless they intend to make the associated investment. This allows us to construct an empirical test for the relevance of loan labels: consistent with the theory, we find that a large proportion of households does not substitute to the cheaper sanitation loan from a more expensive business loan. Second, sensitivity of loan labels implies that households may not increase overall borrowing when the new loan does not fully relax liquidity constraints, and they will instead substitute away from other labelled loans and investments. We show that this is indeed the case in our context: we find that households' overall borrowing did not increase, and there is suggestive evidence of substitution away from education loans.

Our findings have important implications for policy and policy design. Concerns have been raised about the costs and effectiveness of two widely used approaches: CLTS, which mobilises communities and creates awareness about sanitation issues, and the provision of subsidies. Both policies can be very costly, and difficult to target effectively ([Lipscomb and Schechter, 2018, Crocker et al., 2017]), though they have each been shown to be effective (Pickering et al., 2015; Clasen et al., 2014, Patil et al., 2014; Guiteras et al., 2015 among others). Moreover, questions have been raised on the ability of CLTS to boost the take-up of safe sanitation, particularly since it does not relax liquidity constraints (e.g.Abramovsky et al. 2018, Cameron et al. 2013). Further, designing effective subsidy schemes at scale is non-trivial in developing country settings, which are characterised by high informality and low administrative capacity. Sanitation microloans offer another, potentially complementary, policy option. Indeed, our companion paper (Augsburg et al., 2019) shows that this intervention, which coincided by chance with the roll-out of the Government of India's SBM policy, supported this policy by providing financing for households that were ineligible for SBM subsidies, and bridge funding for subsidy eligible households who could avail of the full subsidy only after constructing the toilet.

We are not the first to show that the provision of credit can be effective in increasing sanitation coverage. BenYishay et al. [2017] showed that microcredit increased the demand for toilet construction materials when offered together. However, they find a lower loan-to-new toilet conversion rate of 30-40\%, despite doorstep delivery of construction materials. Our study finds a higher conversion rate (though lower overall demand for sanitation loans), that is achieved by offering a loan only, and allowing households to construct a toilet of its own choice. Beyond the different contexts, the two studies attracted different types of households, which could also potentially explain the differences in findings. This could be due to differences in the liability structure of the microcredit, shown to attract different types of clients (Attanasio et al., 2015b) and/or differences in how the loans were offered. Disentangling which of these 
reasons - differences in contexts, composition of loan-takers, and differences in product design - drives the differences in findings across the two studies is left to future research.

Our findings raise other issues that deserve further consideration in future research. First, we find that a significant proportion, possibly as high as 40-50 percent, or sanitation loans were not used for sanitation investments. While this is consistent with the theory - that households who are not sufficiently sensitive to the loan label will respond to the lower interest rate on the loan -, it could also be a consequence of constraints that are not alleviated by the intervention (e.g. additional liquidity constraints). Second, we find suggestive evidence of substitution away from education loans, which raises questions about potential unintended consequences on education investments that we are unable to investigate in our data. Finally, while the intervention has economically meaningful impacts that lie within the range of other interventions evaluated, it is unlikely by itself to 'solve the sanitation crisis'. Though microfinance coverage is widespread in rural India, fewer than $10 \%$ of households in study GPs have a member that is a client of the implementing MFI. Furthermore, a large proportion of client households without a toilet did not take the loan and/or did not use the sanitation loan for sanitation investment. Identifying the underlying reasons for this is left to future research. 


\section{References}

J. Abeler, D. Nosenzo, and R. Raymond. Preferences for truth-telling. Econometrica, Forthcoming.

Johannes Abeler and Felix Marklein. Fungibility, Labels, and Consumption. Journal of the European Economic Association, 15(1):99-127, 2017.

Johannes Abeler, Anke Becker, and Armin Falk. Representative evidence on lying costs. Journal of Public Economics, 113:96 - 104, 2014. ISSN 0047-2727.

Laura Abramovsky, Britta Augsburg, and Francisco Oteiza. Sustainable Total Sanitation - Nigeria Endline Report. Technical report, Institute for Fiscal Studies, 2018.

U. Afzal, G. d'Adda, M. Fafchamps, S. Quinn, and F. Said. When Nudge Comes to Shove: Demand for Commitment in Microfinance Contracts. December 2018.

Manuela Angelucci, Dean Karlan, and Jonathan Zinman. Microcredit Impacts: Evidence from a Randomized Microcredit Program Placement Experiment by Compartamos Banco. American Economic Journal: Applied Economics, 7(1):151-82, January 2015.

O.P. Attanasio, B. Augsburg, B. Caeyers, B. Malde, and B. Oerez-Viana. Incentivizing Sanitation Uptake and Sustainable Usage through Micro Health Insurance Impact Evaluation 2014, 2015a. [Online; accessed 07-June-2019].

Orazio Attanasio, Britta Augsburg, Ralph De Haas, Emla Fitzsimons, and Heike Harmgart. The Impacts of Microfinance: Evidence from Joint-Liability Lending in Mongolia. American Economic Journal: Applied Economics, 7(1):90-122, January 2015b.

Orazio Attanasio, Britta Augsburg, Bet Caeyers, Sara Giunti, and Bansi Malde. Incentivizing Sanitation Uptake and Sustainable Usage through Microfinance - Endline Report. Mimeo, IFS, 2018.

Britta Augsburg and Paul Andres Rodriguez-Lesmes. Sanitation and Child Health in India. World Development, 107:22-39, 2018.

Britta Augsburg, Bet Caeyers, and Bansi Malde. Can Micro-Credit Support Public Health Subsidy Programs. Mimeo, IFS, 2019.

A. Banerjee, D. Karlan, and J. Zinman. Six Randomized Evaluations of Microcredit: Introduction and Further Steps. American Economic Journal: Applied Economics, 7:1-21, 2015a.

Abhijit Banerjee, Esther Duflo, Rachel Glennerster, and Cynthia Kinnan. The Miracle of Microfinance? Evidence from a Randomized Evaluation. American Economic Journal: Applied Economics, 7(1): 22-53, January 2015b.

S. Barnard, P. Routray, F. Majorin, R. Peletz, S. Boisson, A. Sinha, and T. Clasen. Impact of Indian Total Sanitation Campaign on latrine coverage and use: a cross-sectional study in Orissa three years following programme implementation. PLoS One, 8, 2013. 
J. Bauchet, C. Marshal, L. Starita, J. Thomas, and A. Yalouris. Latest Findings from Randomized Evaluations of Microfinance. Technical report, Consultative Group to Assist the Poor/The World Bank, 2011.

Roland Benabou and Jean Tirole. Willpower and Personal Rules. Journal of Political Economy, 112 (4):848-886, 2004.

Najy Benhassine, Florencia Devoto, Esther Duflo, Pascaline Dupas, and Victor Pouliquen. Turning a Shove into a Nudge? A "Labeled Cash Transfer" for Education. American Economic Journal: Economic Policy, 7(3):86-125, August 2015.

Ariel BenYishay, Andrew Fraker, Raymond Guiteras, Giordano Palloni, Neil Buddy Shah, Stuart Shirrell, and Paul Wang. Microcredit and willingness to pay for environmental quality: Evidence from a randomized-controlled trial of finance for sanitation in rural Cambodia. Journal of Environmental Economics and Management, 86:121-140, 2017.

T. Besley. Nonmarket institutions for credit and risk sharing in low-income countries. Journal of Economic Perspectives, 9:115-127, 1995.

Lisa Cameron, Manisha Shah, and Susan Olivia. Impact Evaluation of a Large-Scale Rural sanitation Project in Indonesia. Technical report, World Bank Policy Research Working Paper, 2013.

Thomas Clasen, Sophie Boisson, Parimita Routray, Belen Torondel, Melissa Bell, Oliver Cumming, Jeroen Ensink, Matthew Freeman, Marion Jenkins, Mitsunori Odagiri, Subhajyoti Ray, Antara Sinha, Mrutyunjay Suar, and Wolf-Peter Schmidt. Effectiveness of a Rural Sanitation Programme on Diarrhoea, Soil-Transmitted Helminth Infection and Child Malnutrition in Odisha, India: A ClusterRandomised Trial. Lancet Global Health, 2:645-53, 2014.

J Crocker, D Saywell, KF Shields, P Kolsky, and J Bartram. The true costs of participatory sanitation: Evidence from community-led total sanitation studies in Ghana and Ethiopia. The Science of the Total Environment, (601-602):1075-1083, 2017.

G. De Arcangelis, M. Joxhe, D. McKenzie, E. Tiongson, and D. Yang. Directing Remittances to Education with Soft and Hard Commitments: Evidence from a Lab-in-the-field Experiment and New Product Take-up Among Filipino Migrants Program. NBER Working Paper No. 20839, January 2015.

Florencia Devoto, Esther Duflo, Pascaline Dupas, William Pariente, and Vincent Pons. Happiness on Tap: Piped Water Adoption in Urban Morocco. American Economic Journal: Economic Policy, 4 (4):68-99, November 2012.

Katherine L. Dickinson, Sumeet R. Patil, Subhrendu K. Pattanayak, Christine Poulos, and Jui-Hen Yang. Nature's Call: Impacts of Sanitation Choices in Orissa, India. Economic Development and Cultural Change, 64(1):1-29, 2015. 
Pascaline Dupas. Health Behavior in Developing Countries. Annual Review of Economics, 3(1):425-449, 2011.

Pascaline Dupas and Jonathan Robinson. Why Don't the Poor Save More? Evidence from Health Savings Experiments. American Economic Review, 103(4):1138-71, June 2013.

E. Field, R. Pande, J. Papp, and N. Rigol. Does the Classic Microfinance Model Discourage Entrepreneurship Among the Poor? Experimental Evidence from India. American Eocnomic Review, 103:2196-2226, 2013.

J.V. Garn, G.D. Sclar, M.C. Freeman, G. Penakalapati, K.T. Alexander, P. Brooks, E.A. Rehfuess, S. Boisson, K.O. Medlicott, and T.F. Clasen. The impact of sanitation interventions on latrine coverage and latrine use: A systematic review and meta-analysis. Int J Hyg Environ Health, 220: 329-340, 2017.

Uri Gneezy. Deception: The Role of Consequences. American Economic Review, 95(1):384-394, March 2005.

Government of India GoI. Population by Sex and Residence, Census 2011. Provisional Population Totals Paper 2 of 2011: India (Vol II)., 2011a. URL http://censusindia.gov.in.

Government of India GoI. District Census Handbook - Latur, 2011b. URL http://censusindia.gov.in/2011census/dchb.

Government of India GoI. District Census Handbook - Nanded, 2011c. URL http://www. censusindia.gov. in/2011census/dchb.

Government of Maharashtra GoM. Maharashtra Human Development Report 2012, 2012.

Government of Maharashtra GoM. Economic Survey of Maharashtra 2017-18, 2018. URL https://mahades.maharashtra.gov.in/files/publication.

D.B Gross and N.S Souleles. Do Liquidity Constraints and Interest Rates Matter for Consumer Behavior? Evidence from Credit Card Data . The Quarterly Journal of Economics, 117:149-185, 2002.

Raymond Guiteras, James Levinsohn, and Ahmed Mushfiq Mobarak. Encouraging sanitation investment in the developing world: A cluster-randomized trial. Science, 348(6237):903-906, 2015.

Raymond Guiteras, David Levine, Thomas Polley, and Brian Quistorff. Credit Constraints, Discounting and Investment in Health: Evidence from Micropayments for Clean Water in Dhaka. North Carolina State University, 2016.

Justine Hastings and Jesse M Shapiro. How are SNAP benefits spent? Evidence from a retail panel. American Economic Review, 108(12):3493-3540, 2018.

P.W. Henderson and R.A. Peterson. Mental Accounting and Categorization. Organizational Behavior and Human Decision Processes, 51:92-117, 1992. 
J. Hines and R.H. Thaler. Anomalies - the flypaper effect. Journal of Economics Perspectives, 9: 217-226, 1995.

William Jack, Michael Kremer, Joost de Laat, and Tavneet Suri. Borrowing Requirements, Credit Access, and Adverse Selection: Evidence from Kenya. Technical report, Working paper, 2017.

Dean Karlan and Leigh L. Linden. Loose knots: Strong versus weak commitments to save for education in uganda. mimeo, Northwestern University, 2018. Online; accessed 08-July-2019.

Dean Karlan and Jonathan Zinman. Lying About Borrowing. Journal of the European Economic Association, 6(2-3):510-521, 2008.

Alexander K. Koch and Julia Nafziger. Goals and bracketing under mental accounting. Journal of Economic Theory, 162:305 - 351, 2016. ISSN 0022-0531.

Santosh Kumar and Sebastian Vollmer. Does Access To Improved Sanitation Reduce Childhood Diarrhoea in Rural India? Health Economics, 22(4):410-427, 2013.

Molly Lipscomb and Laura Schechter. Subsidies versus mental accounting nudges: Harnessing mobile payment systems to improve sanitation. Journal of Development Economics, 135:235-254, 2018.

David McKenzie. Beyond baseline and follow-up: The case for more $\mathrm{T}$ in experiments. Journal of Development Economics, 99(2):210-221, 2012.

Ministry of Drinking Water and Sanitation. Guidelines for Swachh Bharat Mission (Gramin), 2014.

J. Morduch. The Microfinance Promise. 37(4):1569-1614, 1999.

Sumeet R. Patil, Benjamin F. Arnold, Alicia L. Salvatore, Bertha Briceno, Sandipan Ganguly, John M. Colford, Jr, and Paul J. Gertler. The Effect of India's Total Sanitation Campaign on Defecation Behaviors and Child Health in Rural Madhya Pradesh: A Cluster Randomized Controlled Trial. PLOS Medicine, 11(8):1-17, 082014.

Rachel Peletz, Alicea Cock-Esteb, Dorothea Ysenburg, Salim Haji, Ranjiv Khush, and Pascaline Dupas. Supply and Demand for Improved Sanitation: Results from Randomized Pricing Experiments in Rural Tanzania. Environmental Science 83 Technology, 51(12):7138-7147, 2017. PMID: 28562018.

Rachel Peletz, Joyce Kisiangani, Patrick Ronoh, Alicea Cock-Esteb, Claire Chase, Ranjiv Khush, and Jill Luoto. Assessing the Demand for Plastic Latrine Slabs in Rural Kenya. 101(3):555-565, 2019.

Amy Pickering, Habiba Djebbari, Carolina Lopez, Massa Coulibaly, and Maria Laura Alzua. Effect of a Community-Led Sanitation Intervention on Child Diarrhoea and Child Growth in Rural Mali: A Cluster-Randomised Controlled Trial. Lancet Global Health, 3(11):701-711, 2015.

Joseph P. Romano and Michael Wolf. Stepwise Multiple Testing as Formalized Data Snooping. Econometrica, 73(4):1237-1282, 2005. 
Hersh M. Shefrin and Richard H. Thaler. The behavioral life-cycle hypothesis. Economic Inquiry, 26: 609-643, 1988.

Dean Spears. Effects of Rural Sanitation on Infant Mortality and Human Capital: Evidence from India's Total Sanitation Campaign. Princeton University Working Paper, 2012.

Dean Spears and Sneha Lamba. Effects of Early-Life Exposure to Sanitation on Childhood Cognitive Skills: Evidence from India's Total Sanitation Campaign. Journal of Human Resources, 2015.

Alessandro Tarozzi, Aprajit Mahajan, Brian Blackburn, Dan Kopf, Lakshmi Krishnan, and Joanne Yoong. Micro-loans, Insecticide-Treated Bednets, and Malaria: Evidence from a Randomized Controlled Trial in Orissa, India. American Economic Review, 104(7):1909-41, July 2014.

Alessandro Tarozzi, Jaikishan Desai, and Kristin Johnson. The Impacts of Microcredit: Evidence from Ethiopia. American Economic Journal: Applied Economics, 7(1):54-89, January 2015.

Richard H. Thaler. Anomalies: Saving, fungibility, and mental accounts. The Journal of Economic Perspectives, 4:193-205, 1990.

Richard H. Thaler. Mental accounting matters. Journal of Behavioral Decision Making, 12(3):183-206, 1999.

Richard H. Thaler and Cass R. Sunstein. Nudge: Improving Decisions About Health, Wealth, and Happiness. Yale University Press, New Haven, CT, 2008.

Christopher Udry. Risk and insurance in a rural credit market: an empirical investigation in Northern Nigeria. Review of Economic Studies, 61:495-526, 1994.

WHO/UNICEF. Progress on drinking water and sanitation: 2014 Update. World Health Organization and UNICEF, 2014.

WHO/UNICEF. Progress on drinking water, sanitation and hygiene: 2017 Update and SDG Baselines. World Health Organization and UNICEF, 2017.

C. Zhang and A.B. Sussman. The Role of Mental Accounting in Household Spending and Investing Decisions. In C. Chaffin, editor, Client Psychology, chapter 19-07. Wiley, New York, 2004. 


\section{Appendix}

\section{A MFI Loan products}

Table A.1 provides information on main loan products offered by the MFI.

Table A.1: Credit products offered by the MFI

\begin{tabular}{|c|c|c|c|c|c|c|c|}
\hline \multirow[t]{2}{*}{ Product } & \multicolumn{2}{|c|}{ Loan Amout } & \multirow{2}{*}{ Interest rate $(\%)$} & \multirow{2}{*}{ Tenure (weeks) } & \multirow{2}{*}{ Frequency } & \multirow{2}{*}{ Cost $(\%$ loan amount $)$} & \multirow{2}{*}{ Weekly instalment (INR) } \\
\hline & Min & $\operatorname{Max}$ & & & & & \\
\hline Education & 5000 & 15000 & 22 (later 18 ) & 52 & Weekly & 13.4 (later 11.3) & 218 (later 214 - loan amount 10000) \\
\hline Emergency & 1000 & 1000 & 0 & $10 / 11$ & Weekly & 0 & 100 \\
\hline Festival & 2000 & 2000 & 22 (later 18) & 24 & Weekly & 22.4 (later 9.2 ) & 102 (later 91) \\
\hline IGL Pragati Plus (Business) & 15000 & 50000 & 25 (later 22) & 104 & Weekly & 28.1 (later 24.8) & 308 (later 300 - loan amount 25000) \\
\hline IGL Pragati (Business) & 10000 & 20000 & 25 (later 22) & 52 & Weekly & 15.1 (later 13.6) & 332 (later 328 - loan amount 15000 ) \\
\hline Pragati Suppliment Loan & 5000 & 10000 & 26 (later 22) & 52 & Weekly & 15.4 (later 13.4) & 222 (later 218 - loan amount 10000 ) \\
\hline Sanitation Loan & 10000 & 15000 & 22 (later 18) & 104 & Weekly & 24.1 (later 19.9) & 179 (later 173 ) \\
\hline
\end{tabular}

\section{B Sampling description and study area}

The sample was selected from 81 eligible study GPs. An eligible GP was defined as one where (i) the MFI had active lending groups (kendra) and (ii) where sanitation activities had not been undertaken in the past. Through interactions with MFI staff, we identified areas where no sanitation activities were ongoing but they were planned (and/or considered feasible) in the near future. We excluded kendras located in urban areas; and identified GPs with active kendras. This resulted in 81 GPs in five blocks (corresponding to MFI branches) within two districts. Within each GP the following sampling procedure was applied at endline:

Step 1: in the GPs where only one kendra is present, we sampled all clients in that kendra

Step 2: in the GPs where more than one kendra is present, we retained kendras with at least one client sampled at the baseline, and randomly selected one kendra. All client households from that kendra were included in the sample.

Step 3: As more clients were needed to reach the desired sample size, we further randomly sampled the kendras with at least one client sampled at baseline that were not fully sampled until we reached the desired sample size.

Figure 2 shows location of Latur and Nanded within Maharasthra (left) and of study GPs within the two districts (right).

\section{Multiple Hypothesis Testing}

Given that our analysis conducts several hypothesis tests, it is possible that we may falsely reject the null hypothesis when it is true for some hypotheses since the probability of conducting at least one Type I error increases with the number of hypotheses tested. We therefore verify whether our results 
Figure 2: Study location

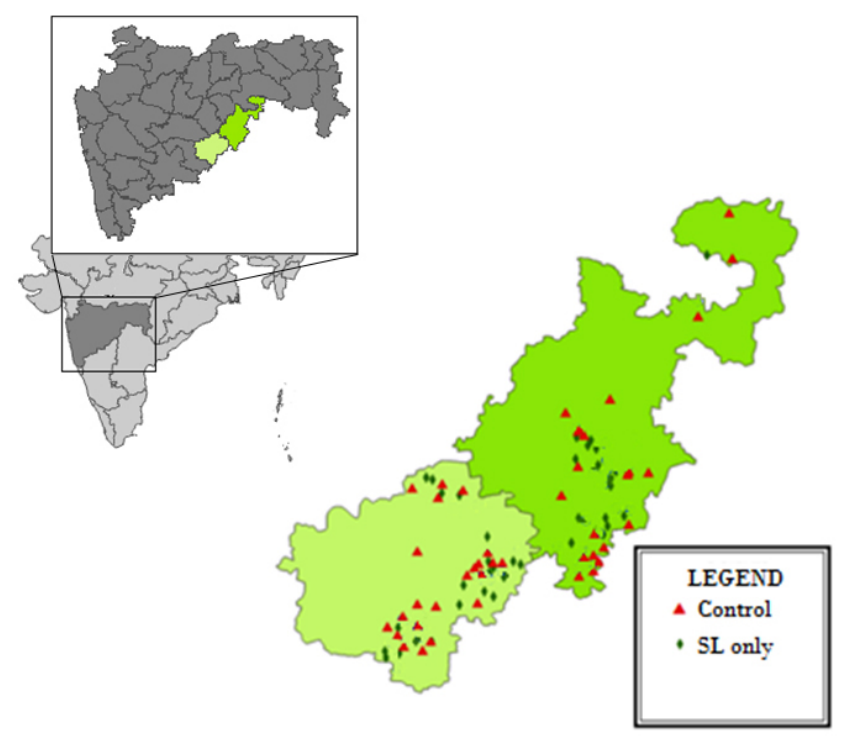

Notes: Figure shows location of Latur and Nanded within Maharasthra (left) and of study GPs within the two districts (right).

hold once we account for multiple hypothesis testing by calculating adjusted p-values according to the procedure of [Romano and Wolf, 2005]. Table C.1 displays the impact estimates and standard errors for all outcomes in the two rows before reporting the original p-values (3rd row) and those adjusted for multiple hypotheses (4th row). The Table shows that the impacts on the key outcomes of interest are robust to multiple hypothesis testing.

\section{Additional Tables}

Table D.1 displays the loan-to-new toilet conversion regressions.

Table D.2 displays impacts on business ownership and closure. We consider impacts on the likelihood of the household owning any type of business (column 1), an agricultural business ${ }^{37}$ (column 3) or whether it went through a business closure (column 2) during the experiment. We do not detect any significant changes of the intervention on these outcomes. Impact estimates on the likelihood of households making a large business investment (column 4) and on reported profits (column 5) are also statistically insignificant from zero, indicating that the sanitation loans did not induce new business investments. Interestingly, all estimated coefficients are negative, suggesting some substitution out of these productive investments, which would be in line with the case highlighted in the model where

\footnotetext{
${ }^{37}$ Agricultural business covers crop and animal husbandry.
} 
Table C.1: Intervention impact on all outcomes

\begin{tabular}{|c|c|c|c|c|c|c|c|}
\hline & $(1)$ & $(2)$ & $(3)$ & (4) & $(5)$ & (6) & $(7)$ \\
\hline & $\begin{array}{c}\text { Sanitation } \\
\text { Loan }\end{array}$ & Own toilet & $\begin{array}{c}\text { Own } \\
\text { functioning } \\
\text { toilet }\end{array}$ & \multicolumn{3}{|c|}{ Toilet quality } & $\begin{array}{c}\text { Open } \\
\text { defecation }\end{array}$ \\
\hline & & \multicolumn{2}{|c|}{ Interviewer observation } & Underground & Overground 1 & Overground 2 & $\begin{array}{c}\text { All HH } \\
\text { members }\end{array}$ \\
\hline SL & $\begin{array}{l}0.182^{* * *} \\
(0.0358)\end{array}$ & $\begin{array}{l}0.0899^{* *} \\
(0.0244)\end{array}$ & $\begin{array}{c}0.0958^{* * *} \\
(0.0232)\end{array}$ & $\begin{array}{c}0.0140 \\
(0.0219)\end{array}$ & $\begin{array}{c}0.0631 \\
(0.0342)\end{array}$ & $\begin{array}{c}0.0519 \\
(0.0272)\end{array}$ & $\begin{array}{c}-0.108^{* * *} \\
(0.0252)\end{array}$ \\
\hline Cluster-robust p-value & {$[0.0000]$} & {$[0.0002]$} & {$[0.0000]$} & {$[0.5227]$} & \multirow{2}{*}{$\begin{array}{l}{[0.0653]} \\
{[0.5065]}\end{array}$} & {$[0.0566]$} & {$[0.0000]$} \\
\hline Romano-Wolf p-value & {$[0.0000]$} & {$[0.0050]$} & {$[0.0020]$} & {$[0.9970]$} & & {$[0.4825]$} & {$[0.0010]$} \\
\hline Covariates & Yes & Yes & Yes & Yes & Yes & Yes & Yes \\
\hline Control mean & 0.0133 & 0.413 & 0.372 & 1.380 & \multirow{2}{*}{$\begin{array}{c}2.434 \\
1281\end{array}$} & 0.369 & 0.603 \\
\hline $\mathrm{N}$ & 2821 & 2821 & 2821 & 1281 & & 1281 & 2821 \\
\hline & $(8)$ & $(9)$ & $(10)$ & (11) & $(12)$ & (13) & (14) \\
\hline & $\begin{array}{c}\text { Open } \\
\text { defecation }\end{array}$ & \multicolumn{5}{|c|}{ Borrowing } & \\
\hline & $\begin{array}{l}\text { Any HH } \\
\text { member }\end{array}$ & Sanitation & Business & Education & Emergency & Consumption & Total \\
\hline SL & $\begin{array}{c}-0.105^{* * *} \\
(0.0249)\end{array}$ & $\begin{array}{c}2654.4^{* * *} \\
(527.4)\end{array}$ & $\begin{array}{c}988.0 \\
(2252.9)\end{array}$ & $\begin{array}{l}-477.3 \\
(871.5)\end{array}$ & $\begin{array}{c}107.3 \\
(143.8)\end{array}$ & $\begin{array}{c}46.89 \\
(99.66)\end{array}$ & $\begin{array}{c}-465.3 \\
(1845.8)\end{array}$ \\
\hline Cluster-robust p-value & {$[0.0000]$} & {$[0.0000]$} & {$[0.6610]$} & {$[0.5840]$} & {$[0.4559]$} & {$[0.6381]$} & {$[0.8010]$} \\
\hline Romano-Wolf p-value & {$[0.0010]$} & {$[0.0000]$} & {$[0.9970]$} & {$[0.9970]$} & {$[0.9970]$} & {$[0.9970]$} & {$[0.9980]$} \\
\hline Covariates & Yes & Yes & Yes & Yes & Yes & Yes & Yes \\
\hline Control mean & 0.610 & 199.9 & 37871.2 & 8314.7 & 699.9 & 362.9 & 31744.3 \\
\hline \multirow[t]{4}{*}{$\mathrm{N}$} & 2821 & 2821 & 2821 & 2821 & 2821 & 2821 & 2793 \\
\hline & $\overline{(15)}$ & (16) & $(17)$ & (18) & (19) & $\overline{(20)}$ & $(21)$ \\
\hline & \multicolumn{3}{|c|}{ Borrowing } & & \multirow[t]{2}{*}{ Benefits } & \multicolumn{2}{|c|}{ Costs } \\
\hline & Formal & MFIs & Other formal & Informal & & Component 1 & Component 2 \\
\hline SL & $\begin{array}{c}-99.14 \\
(1877.3)\end{array}$ & $\begin{array}{c}336.5 \\
(1533.1)\end{array}$ & $\begin{array}{c}-435.6 \\
(1578.3)\end{array}$ & $\begin{array}{l}-366.1 \\
(399.8)\end{array}$ & $\begin{array}{l}0.00837 \\
(0.0488)\end{array}$ & $\begin{array}{c}0.0534 \\
(0.0973)\end{array}$ & $\begin{array}{r}-0.00967 \\
(0.0436)\end{array}$ \\
\hline Cluster-robust p-value & {$[0.9579]$} & {$[0.8263]$} & {$[0.7826]$} & [0.3599] & {$[0.8640]$} & {$[0.5834]$} & {$[0.8248]$} \\
\hline Romano-Wolf p-value & {$[0.9980]$} & {$[0.9980]$} & {$[0.9980]$} & {$[0.9850]$} & {$[0.9980]$} & {$[0.9970]$} & {$[0.9980]$} \\
\hline Covariates & Yes & Yes & Yes & Yes & Yes & Yes & Yes \\
\hline Control mean & 29379.7 & 14969.7 & 14409.9 & 2364.6 & 10.88 & 6.869 & -0.557 \\
\hline $\mathrm{N}$ & 2793 & 2793 & 2793 & 2793 & 2723 & 2723 & 2723 \\
\hline
\end{tabular}

households are sensitive to loan labels and the sanitation loan does not sufficiently relax liquidity constraints.

Unfortunately, our data does not allow us to get a detailed enough picture on consumption expenditures over the study period, a relevant indicator given that existing evidence suggests that a significant proportion of microfinance loans are used for consumption purposes ([Banerjee et al., 2015a]) and households might also rely on microfinance and informal borrowing sources to fund unexpected consumption expenditures following unanticipated shocks ([Besley, 1995, Udry, 1994]). We only have information on total food and non-food expenditures in the week prior to the endline survey, rather than when the loans were taken. For completeness, Table D.3 displays impact estimates on these outcomes in levels, for the whole sample, and excluding the top $1 \%$ of the distribution. ${ }^{38}$ We do not find any significant impacts of the intervention on these outcomes. Impacts on non-food expenditures in the week prior to the endline survey are significantly negative at the $10 \%$ significance level. This does however not

\footnotetext{
${ }^{38}$ We also estimate impacts on $\log$ and inverse hyperbolic transformation (since non-food expenditures are zero for 105 households) of expenditures. Results do not change.
} 
Table D.1: Loan-to-new-toilet conversion

\begin{tabular}{|c|c|c|}
\hline & $\begin{array}{l}\text { (1) } \\
\text { Interviewer } \\
\text { observation } \\
\quad \text { OLS }\end{array}$ & $(2)$ \\
\hline \multicolumn{3}{|l|}{ Second stage } \\
\hline Sanitation loan uptake & $\begin{array}{c}0.1474^{* * *} \\
(0.0347)\end{array}$ & $\begin{array}{c}0.4948^{* * *} \\
(0.1476)\end{array}$ \\
\hline $\begin{array}{l}\text { Covariates } \\
\text { r2 }\end{array}$ & $\begin{array}{c}\text { Yes } \\
0.430\end{array}$ & $\begin{array}{c}\text { Yes } \\
0.394\end{array}$ \\
\hline \multicolumn{3}{|l|}{ First stage } \\
\hline SL - First stage & & $\begin{array}{c}0.1818^{* * *} \\
(0.0356)\end{array}$ \\
\hline F-stat & & 25.8029 \\
\hline $\mathrm{N}$ & 2821 & 2821 \\
\hline \multicolumn{3}{|c|}{$\begin{array}{l}\text { Notes: Notes: SL equals sanitation loan arm. Standard errors } \\
\text { clustered at the village level are shown in parentheses. } *, * *, * * * \\
\text { indicate significance at the } 10,5 \text { and } 1 \text { percent level. Covariates: } \\
\text { See Table } 3 \text { Note. Data source: household survey. }\end{array}$} \\
\hline
\end{tabular}

Table D.2: Intervention impact on business investments

\begin{tabular}{|c|c|c|c|c|c|}
\hline & $\begin{array}{c}\text { (1) } \\
\text { Business } \\
\text { ownership }\end{array}$ & $\begin{array}{c}(2) \\
\text { Business } \\
\text { closed }\end{array}$ & $\begin{array}{c}\text { (3) } \\
\text { Agricultural } \\
\text { business }\end{array}$ & $\begin{array}{c}(4) \\
\text { Large } \\
\text { investment }\end{array}$ & Profits \\
\hline $\mathrm{SL}$ & $\begin{array}{l}-0.0225 \\
(0.0456)\end{array}$ & $\begin{array}{l}-0.00112 \\
(0.00709)\end{array}$ & $\begin{array}{c}0.000317 \\
(0.0360)\end{array}$ & $\begin{array}{l}-0.0175 \\
(0.0191)\end{array}$ & $\begin{array}{c}-104.4 \\
(1127.4)\end{array}$ \\
\hline $\begin{array}{l}\text { Cluster-robust p-value } \\
\text { Romano-Wolf p-value }\end{array}$ & $\begin{array}{l}{[0.6225]} \\
{[0.9620]}\end{array}$ & $\begin{array}{l}{[0.8742]} \\
{[0.9930]}\end{array}$ & $\begin{array}{l}{[0.9930]} \\
{[0.9950]}\end{array}$ & $\begin{array}{l}{[0.3598]} \\
{[0.7952]}\end{array}$ & $\begin{array}{l}{[0.9263]} \\
{[0.9950]}\end{array}$ \\
\hline Covariates & Yes & Yes & Yes & Yes & Yes \\
\hline $\begin{array}{l}\text { Control mean } \\
\mathrm{N}\end{array}$ & $\begin{array}{l}0.449 \\
2821\end{array}$ & $\begin{array}{c}0.0286 \\
2821\end{array}$ & $\begin{array}{l}0.235 \\
2821\end{array}$ & $\begin{array}{l}0.143 \\
2821\end{array}$ & $\begin{array}{c}7262.4 \\
2764\end{array}$ \\
\hline \multicolumn{6}{|c|}{$\begin{array}{l}\text { Notes: SL equals sanitation loan arm. Standard errors clustered at the village level are shown in parentheses. } \\
*, * *, * * * \text { indicate significance at the } 10,5 \text { and } 1 \text { percent level, referring to Romano-Wolf p-values. Covariates: } \\
\text { See Table } 3 \text { notes. Amounts are in Indian Rupees ( } 1 \text { USD = INR } 67.5) \text {. Data source: household survey. To } \\
\text { remove the influence of outliers, we drop households in the bottom and top } 1 \text { percent of the distribution of } \\
\text { profits. }\end{array}$} \\
\hline
\end{tabular}


Table D.3: Intervention impact on consumption expenditures

\begin{tabular}{|c|c|c|c|c|}
\hline & $\begin{array}{c}(1) \\
\text { Food exp. }\end{array}$ & $\begin{array}{c}(2) \\
\text { Food exp. } \\
\text { (excl. outl.) }\end{array}$ & $\begin{array}{c}(3) \\
\text { Non-food exp. }\end{array}$ & $\begin{array}{c}(4) \\
\text { Non-food exp. } \\
\text { (excl. outl.) }\end{array}$ \\
\hline SL & $\begin{array}{c}45.51 \\
(36.23)\end{array}$ & $\begin{array}{c}25.56 \\
(17.99)\end{array}$ & $\begin{array}{l}-30.35 \\
(60.65)\end{array}$ & $\begin{array}{l}-67.57 \\
(37.79)\end{array}$ \\
\hline $\begin{array}{l}\text { Cluster-robust p-value } \\
\text { Romano-Wolf p-value }\end{array}$ & & $\begin{array}{l}{[0.1555]} \\
{[0.1638]}\end{array}$ & & $\begin{array}{l}{[0.0738]} \\
{[0.1289]}\end{array}$ \\
\hline Covariates & Yes & Yes & Yes & Yes \\
\hline Control mean & 884.2 & 818.9 & 953.0 & 830.8 \\
\hline $\mathrm{N}$ & 2821 & 2759 & 2821 & 2766 \\
\hline
\end{tabular}

Notes: SL equals sanitation loan arm. Standard errors clustered at the village level are shown in parentheses. ${ }^{*}, * *, * * *$ indicate significance at the 10,5 and 1 percent level, referring to Romano-Wolf p-values. Covariates: See Table 3 notes. Amounts are in Indian Rupees (1 USD = INR 67.5). Data source: household survey. To remove the influence of outliers, we drop households in top 1 percent of the distribution in columns 2 and 4 (excl. outl.).

survive multiple hypothesis testing.

\section{E Proofs}

\section{Proof to Proposition 2:}

Proposition 2: The lower interest rate reduces the cost of making investments. For households with $\kappa<\kappa^{*}$, either investment can now be made at a lower cost, resulting in an increase in both sanitation and business investments. By contrast, for households with $\kappa \geq \kappa^{*}$ that need to borrow to make any investment, the lower interest rate will reduce the cost of making sanitation investments, especially when they only invest in one good. Thus compared to households with $\kappa<\kappa^{*}$, the lower interest sanitation loan will lead to a larger increase in sanitation investments.

Proof:

To derive this proposition, we compare the investment choices households make when the sanitation loan is offered at the interest rate of $r_{e}$ with those made when it is offered at the interest rate of $r_{s}$. The household obtains the following payoffs for each possible combination of investment choices when the interest rate on the sanitation loan is set as $r_{s}$ :

$$
\begin{aligned}
& E U_{11}\left(b_{s, y_{1}}^{11}, b_{e, y_{1}}^{11}\right)=y_{1}-p_{e}-p_{s}+b_{s, y_{1}}^{11}+b_{e, y_{1}}^{11}+\beta\left[E\left(y_{2}\right)+\gamma+\theta-\left(1+r_{e}\right) b_{e, y_{1}}^{11}-\left(1+r_{s}\right) b_{s, y_{1}}^{11}\right] \\
& E U_{10}\left(b_{s, y_{1}}^{10}, b_{e, y_{1}}^{10}\right)=y_{1}-p_{e}+b_{s, y_{1}}^{10}+b_{e, y_{1}}^{10}-\kappa b_{s, y_{1}}^{10}+\beta\left[E\left(y_{2}\right)+\theta-\left(1+r_{s}\right) b_{s, y_{1}}^{10}-\left(1+r_{e}\right) b_{e, y_{1}}^{10}\right] \\
& E U_{01}\left(b_{s, y_{1}}^{01}, b_{e, y_{1}}^{01}\right)=y_{1}-p_{s}+b_{s, y_{1}}^{01}+b_{e, y_{1}}^{01}-\kappa b_{e}^{01}+\beta\left[E\left(y_{2}\right)+\gamma-\left(1+r_{s}\right) b_{s, y_{1}}^{01}-\left(1+r_{e}\right) b_{e, y_{1}}^{01}\right] \\
& E U_{00}\left(b_{s, y_{1}}^{00}, b_{e, y_{1}}^{00}\right)=y_{1}+b_{s, y_{1}}^{00}-\kappa b_{s, y_{1}}^{00}+\beta\left[E\left(y_{2}\right)-\left(1+r_{s}\right) b_{s, y_{1}}^{00}\right]
\end{aligned}
$$

Notice that the household might choose to borrow the sanitation loan when it does not intend to make any investments in order to bring forward consumption to the first period when $r_{s}<r_{e}$ and $\beta\left(1+r_{s}\right)<1$. 
Next, we derive the conditions under which each possible combination of investment choices would be made. The household will make the sanitation investment only if $E U_{01}-E U_{00} \geq 0$. This is satisfied when $\beta \gamma \geq p_{s}+\kappa\left(b_{e, y_{1}}^{01}-b_{s, y_{1}}^{00}\right)-\left(1-\beta\left(1+r_{s}\right)\right)\left(b_{s, y_{1}}^{01}-b_{s, y_{1}}^{00}\right)$. In addition, $E U_{11}-E U_{01}<0$, which is satisfied when $\beta \theta<p_{e}-\kappa b_{e, y_{1}}^{01}-\left(1-\beta\left(1+r_{s}\right)\right)\left(b_{s, y_{1}}^{11}-b_{s, y_{1}}^{01}\right)$.

It will choose to make only the business investment if $E U_{10}-E U_{00} \geq 0$, which is satisfied when $\beta \theta \geq p_{e}+\kappa\left(b_{s, y_{1}}^{10}-b_{s, y_{1}}^{00}\right)-\left(1-\beta\left(1+r_{s}\right)\right)\left(b_{s, y_{1}}^{10}-b_{s, y_{1}}^{00}\right)$. In addition, $E U_{11}-E U_{10}<0$, which is satisfied when $\beta \gamma<p_{s}-\kappa b_{s, y_{1}}^{01}-\left(1-\beta\left(1+r_{s}\right)\right)\left(b_{s, y_{1}}^{11}-b_{s, y_{1}}^{10}\right)$.

Finally, it will choose to make both investments if $E U_{11}-E U_{10} \geq 0$ and $E U_{11}-E U_{01} \geq 0$. This is satisfied when $\beta \theta \geq p_{e}+\kappa b_{e, y_{1}}^{01}-\left(1-\beta\left(1+r_{s}\right)\right)\left(b_{s, y_{1}}^{11}-b_{s, y_{1}}^{01}\right)$ and $\beta \gamma \geq p_{s}-\kappa b_{s, y_{1}}^{01}-\left(1-\beta\left(1+r_{s}\right)\right)\left(b_{s, y_{1}}^{11}-\right.$ $\left.b_{s, y_{1}}^{10}\right)$.

The investment conditions show a trade-off between diverting a labelled loan to a non-labelled purpose (e.g. using a sanitation loan for a business loan only), which increases the cost of making the investment; and the lower interest rate (whose effect comes through the $\left(1-\beta\left(1+r_{s}\right)\right)$ term), which reduces the cost of making the investment. The direction of the trade-off that prevails depends on the values of $\kappa$ and $1-\beta\left(1+r_{s}\right)=\kappa^{*}$. The effect of the lower interest rate will prevail when $\kappa<\kappa^{*}$, while that of the loan diversion will prevail when $\kappa>\kappa^{*}$. The positive sign on the term associated with $\kappa$ is positive, while that on $1-\beta\left(1+r_{s}\right)$ is negative.

Thus when $\kappa<\kappa^{*}$, the cost of making the either investment is lowered by the lower interest rate on the sanitation loan, leading to an increase in both investments relative to the case when $r_{e}=r_{s}$. However, when $\kappa>\kappa^{*}$, the household cannot take advantage of the lower interest rate on the sanitation loan if it wants to borrow the sanitation loan to make the business investment only. Thus, the lower interest rate on the sanitation loan will encourage sanitation investments among these households when they intend to make one investment only and need to borrow to do so. ${ }^{39}$ Thus, there will be a larger increase in sanitation investments among these households relative to those with $\kappa<\kappa^{*}$.

\section{Proof of Proposition 3}

Proposition 3: When $r_{e}>r_{s}$, there exists a label sensitivity threshold, $\kappa^{*}=\beta\left(r_{e}-r_{s}\right)$ such that households with $\kappa<\kappa^{*}$ will substitute away from the business loan to the sanitation loan, regardless of their investment choices. By contrast, households with $\kappa \geq \kappa^{*}$ will take the sanitation loan only if they intend to make a sanitation investment.

Proof:

We characterise the conditions under which it is optimal for the household to substitute from the business loan to the sanitation loan for all possible investment choices when borrowing constraints do not bind. The latter condition means that we are assessing the effect of the lower interest rate only. Let $E U_{e s}\left(b_{s, y_{1}}^{e s}, b_{e, y_{1}}^{e s}\right)$ denote the household's payoff when making investment choices $e$ and $s$ and borrowing $b_{s, y_{1}}^{e s}$ and $b_{e, y_{1}}^{e s}$ of the sanitation and business loans respectively to do so when it draws an endowment $y_{1}$.

\footnotetext{
${ }^{39}$ Interestingly, this does not hold when the household borrows to make both investments, since the loan diversion penalty would not apply. It can then benefit from the lower interest rate on the sanitation loans even when $\kappa>\kappa^{*}$.
} 
We also assume that $\beta=\frac{1}{1+r_{e}}$. This is done for simplicity, and does not change any of the qualitative predictions of the model.

When the household makes both investments, it will substitute to the sanitation loan if $E U_{11}\left(b_{s, y_{1}}^{11}, b_{e, y_{1}}^{11}\right)-$ $E U_{11}\left(0, b_{e, y_{1}}^{1 \tilde{1}}\right)>0$, where $b_{e, y_{1}}^{\tilde{1} 1}=b_{e, y_{1}}^{11}+b_{s, y_{1}}^{11}$. This is satisfied when

$$
\begin{gathered}
E U_{11}\left(b_{s, y_{1}}^{11}, b_{e, y_{1}}^{11}\right)=y_{1}-p_{e}-p_{s}+b_{s, y_{1}}^{11}+b_{e, y_{1}}^{11}+\beta\left[E\left(y_{2}\right)+\theta+\gamma-\left(1+r_{s}\right) b_{s, y_{1}}^{11}-\left(1+r_{e}\right) b_{e, y_{1}}^{11}\right]> \\
y_{1}-p_{e}-p_{s}+b_{e, y_{1}}^{1 \tilde{1}}+\beta\left[E\left(y_{2}\right)+\theta+\gamma-\left(1+r_{e}\right) b_{e, y_{1}}^{\tilde{11}}\right]=E U_{11}\left(0, b_{e, y_{1}}^{1 \tilde{1}}\right)
\end{gathered}
$$

This simplifies to $\beta b_{s, y_{1}}^{11}\left(r_{e}-r_{s}\right)>0$. Since $r_{e}>r_{s}$, this condition is always satisfied.

When $e=1$ and $s=0$, it is optimal to switch to the sanitation loan if $E U_{10}\left(b_{s, y_{1}}^{10}, b_{e, y_{1}}^{10}\right)-E U_{10}\left(0, b_{e, y_{1}}^{1 \tilde{0}}\right)>$ 0 , where $b_{e, y_{1}}^{1 \tilde{0}}=b_{e, y_{1}}^{10}+b_{s, y_{1}}^{10}$. This implies that

$$
\begin{gathered}
E U_{10}\left(b_{s, y_{1}}^{10}, b_{e, y_{1}}^{10}\right)= \\
y_{1}-p_{e}+b_{s, y_{1}}^{10}+b_{e, y_{1}}^{10}-\kappa b_{s, y_{1}}^{10}+\beta\left[E\left(y_{2}\right)+\theta-\left(1+r_{s}\right) b_{s, y_{1}}^{10}-\left(1+r_{e}\right) b_{e, y_{1}}^{10}\right]> \\
y_{1}-p_{e}+b_{e, y_{1}}^{1 \tilde{0}}+\beta\left[E\left(y_{2}\right)+\theta-\left(1+r_{e}\right) b_{e, y_{1}}^{1 \tilde{0}}\right]=E U_{10}\left(0, b_{e, y_{1}}^{10}\right)
\end{gathered}
$$

This simplifies to $\kappa<\beta\left(r_{e}-r_{s}\right)$.

When $e=0$ and $s=1$, it is optimal to switch to the sanitation loan if $E U_{01}\left(b_{s, y_{1}}^{01}, b_{e, y_{1}}^{01}\right)-E U_{01}\left(0, b_{e, y_{1}}^{0 \tilde{1}}\right)>$ 0 , where $b_{e, y_{1}}^{0 \tilde{1}}=b_{e, y_{1}}^{01}+b_{s, y_{1}}^{01}$. Thus

$$
\begin{gathered}
E U_{01}\left(b_{s, y_{1}}^{01}, b_{e, y_{1}}^{01}\right)=y_{1}-p_{s}+b_{s, y_{1}}^{01}+b_{e, y_{1}}^{01}-\kappa b_{e, y_{1}}^{01}+\beta\left[E\left(y_{2}\right)+\gamma-\left(1+r_{s}\right) b_{s, y_{1}}^{01}-\left(1+r_{e}\right) b_{e, y_{1}}^{01}\right]> \\
y_{1}-p_{s}+b_{e, y_{1}}^{0 \tilde{1}}-\kappa b_{e, y_{1}}^{0 \tilde{1}}+\beta\left[E\left(y_{2}\right)+\gamma-\left(1+r_{e}\right) b_{e, y_{1}}^{0 \tilde{1}}\right]=E U_{01}\left(0, b_{e, y_{1}}^{0 \tilde{1}}\right)
\end{gathered}
$$

which simplifies to $\kappa b_{s, y_{1}}^{01}+\beta b_{s, y_{1}}^{01}\left(r_{e}-r_{s}\right)>0$. Since $r_{e}>r_{s}$, this condition is always satisfied.

When $e=0$ and $s=0$, and $\beta=\frac{1}{1+r_{e}}$, it is optimal not to borrow, and to instead consume one's income in each period. However, since $r_{s}<r_{e}$, the household can gain more utility by borrowing and consuming more in period 1 than in period $2\left(\right.$ since $\left.\beta<\frac{1}{1+r_{s}}\right)$ when $\kappa+\beta\left(1+r_{s}\right)<1$. This condition can be rewritten as $\kappa<\beta\left(r_{s}-r_{e}\right)$.

Combining these conditions, we see that there is a label sensitivity threshold, $\kappa^{*}=\beta\left(r_{e}-r_{s}\right)$ such that when $\kappa<\beta\left(r_{e}-r_{s}\right)$, it is always optimal for the household to switch to the sanitation loan before taking the business loan, regardless of its investment choices. For households with $\kappa>\kappa^{*}$, it is optimal to take the sanitation loan only if they plan to make sanitation investments.

\section{Proof to Proposition 4}

Proposition 4: Overall borrowing must increase if the sanitation loan relaxes overall liquidity constraints, thereby allowing new investments to be made. It will also increase if the lower interest rate encourages 
new investments. It will not increase if either $(i) \kappa<\kappa^{*}$ and households substitute to the lower interest sanitation loan without changing investment decisions, or (ii) $\kappa>\kappa^{*}$ and the household remains liquidity constrained. In this case, take-up of a specific labelled loan and investment would be accompanied by substitution away from other labelled loans and investments.

Proof:

This proposition characterises possible impacts of the sanitation loan on overall borrowing behaviour. The first part - that overall borrowing must increase if the sanitation loan relaxes overall liquidity constraints - follows

Prior to the introduction of the sanitation loan, the household faced a borrowing limit of $b_{e}^{\max }$. This increased it to $b_{e}^{\max }+b_{s}^{\max }$ following the introduction of the sanitation loan, allowing households to borrow more in order to make desired investments. For example, when $y_{1}+b_{e}^{\max }<p_{s}+p_{e}, y_{1}+b_{e}^{\max } \geq p_{s}$, $y_{1}+b_{e}^{\text {max }} \geq p_{e}$ and $\beta \theta \geq p_{e}$ and $\beta \gamma \geq p_{s}$, the household is unable to borrow enough in the absence of the sanitation loan to make both investments (but can borrow enough to make one investment), even though it is beneficial for it to make both. If, in addition, $y_{1}+b_{e}^{\max }+b_{s}^{\max } \geq p_{s}+p_{e}$, the introduction of the sanitation loan will relax its borrowing constraint and allow it to make both the investments. In this case, the household will borrow $b_{e, y_{1}}^{11}+b_{s, y_{1}}^{11}$, which is greater than the $b_{e, y_{1}}^{10}$ or $b_{e, y_{1}}^{01}$ or $b_{e, y_{1}}^{00}$ it might have otherwise borrowed to make either the business or sanitation investments only, or no investment. Similar conditions can be derived for other cases where binding liquidity constraints are relaxed by the sanitation loan. Thus, the household's overall borrowing must increase if the sanitation loan relaxed liquidity constraints.

Similarly, overall borrowing should increase if the lower interest rate encouraged new investments. As shown in proposition 3, the lower interest rate on the sanitation loan lowers the cost of making both, or only sanitation investments depending on the household's value of $\kappa$. It is easy to show that $b_{s, y_{1}}^{11}+b_{s, y_{1}}^{11} \geq b_{e, y_{1}}^{10}+b_{s, y_{1}}^{10}$, or that $b_{s, y_{1}}^{11}+b_{s, y_{1}}^{11} \geq b_{e, y_{1}}^{01}+b_{s, y_{1}}^{01}$, or that $b_{e, y_{1}}^{10}+b_{s, y_{1}}^{10} \geq b_{s, y_{1}}^{00}$, or that $b_{e, y_{1}}^{01}+b_{s, y_{1}}^{01} \geq b_{s, y_{1}}^{00}$. Thus, overall borrowing will increase when the lower interest rate encourages new investments.

The second part of the proposition characterises the cases where overall borrowing will not increase. It would not increase if the household chooses not to make any new investments. However, it might also not increase for households with $\kappa>\kappa^{*}$ for whom $y_{1}+b_{e}^{\max }+b_{s}^{\max }<p_{s}+p_{e}$ and $y_{1}+b_{e}^{\max } \geq p_{s}$, $y_{1}+b_{e}^{\max } \geq p_{e}$. These households are unable to make both investments if desired even after the introduction of the sanitation loan. Nonetheless, the availability of the sanitation labelled loan would encourage households for whom $\left(p_{s}-p_{e}\right)<\beta(\gamma-\theta)<\left(p_{s}-p_{e}\right)+\kappa b_{e, y_{1}}^{01}$, who previously made a business investment rather than a sanitation investment to make the sanitation investment rather than the business investment. These households would also switch away from the business loan to the sanitation loan. In addition, if $p_{s}=p_{e}, b_{s, y_{1}}^{01}+b_{e, y_{1}}^{01}=b_{e, y_{1}}^{10}+b_{s, y_{1}}^{10}$, and so overall borrowing will not increase. 